Published in final edited form as:

Nature. 2015 January 22; 517(7535): 501-504. doi:10.1038/nature13868.

\title{
IgG1 protects against renal disease in a mouse model of cryoglobulinemia
}

\author{
Richard T. Strait ${ }^{1,6}$, Monica T. Posgai ${ }^{5}$, Ashley Mahler ${ }^{1}$, Nathaniel Barasa ${ }^{1}$, Chaim 0. \\ Jacob $^{9}$, Jörg Köhl' ${ }^{2,8}$, Marc Ehlers ${ }^{8}$, Keith Stringer ${ }^{3}$, Shiva Kumar Shanmukappa ${ }^{3}$, David \\ Witte $^{3}$, Md Monir Hossain ${ }^{4}$, Marat Khodoun ${ }^{7}$, Andrew B. Herr ${ }^{2,5}$, and Fred D. Finkelman 2,7,10 \\ ${ }^{1}$ Division of Emergency Medicine, Cincinnati Children's Hospital Medical Center, Cincinnati, $\mathrm{OH}$ \\ 45229
}

2Division of Immunobiology, Cincinnati Children's Hospital Medical Center, Cincinnati, OH 45229

${ }^{3}$ Division of Pathology, Cincinnati Children's Hospital Medical Center, Cincinnati, $\mathrm{OH} 45229$

${ }^{4}$ Division of Biostatistics and Epidemiology, Cincinnati Children's Hospital Medical Center, Cincinnati, $\mathrm{OH} 45229$

${ }^{5}$ Department of Molecular Genetics, Biochemistry and Microbiology, University of Cincinnati College of Medicine, Cincinnati, $\mathrm{OH} 45267$

${ }^{6}$ Department of Pediatrics, University of Cincinnati College of Medicine, Cincinnati, OH 45267

${ }^{7}$ Division of Immunology, Allergy and Rheumatology, Department of Medicine, University of Cincinnati College of Medicine, Cincinnati, OH 45267

${ }^{8}$ Institute for Systemic Inflammation Research, University of Lübeck, 23538 Lübeck, Germany

${ }^{9}$ Department of Medicine, University of Southern California School of Medicine, Los Angeles, CA, 90033

${ }^{10}$ Medical Service, Cincinnati Veterans Affairs Medical Center, Cincinnati, OH 45220

Immunoglobulins (Igs) protect against disease to a considerable extent by activating complement and stimulatory $\mathrm{IgFc}$ receptors (FcRs) and aggregating microbial pathogens ${ }^{1,2}$; yet $\mathrm{IgG1}$, the predominant murine serum Ig isotype, cannot activate complement by the classical pathway, binds more avidly to an inhibitory than to stimulatory FcRs and has

\footnotetext{
Users may view, print, copy, and download text and data-mine the content in such documents, for the purposes of academic research, subject always to the full Conditions of use:http://www.nature.com/authors/editorial_policies/license.html\#terms

Correspondence and requests for materials should be addressed to F.D.F (finkelfd@UCMAIL.UC.EDU).

Extended Data are linked to the online version of the paper at www.nature.com/nature

Author Contributions R.T.S. planned, performed, interpreted and directed all experiments and participated in all drafts of the manuscript; M.K., A.M. and N.B. performed experiments; C.O.J. provided mice; J.K. provided mice and reagents and participated in planning of all complement-related studies; M.E. participated in the planning and interpretation of isotype switch variant studies; S.K.S., K.S. and D.W. performed and interpreted histological studies; M.T. P. and A.B. H. contributed to investigation of the importance of $\mathrm{Ab}$ hinge region length and F.D.F. designed the study, analyzed data and wrote the initial draft of the paper. All authors discussed the results and commented on the manuscript.

Author Information Reprints and permissions information is available at www.nature.com/reprints.

The authors have no competing financial interests.
} 
limited ability to aggregate pathogens. ${ }^{1-3}$ In these regards, it resembles human IgG4. ${ }^{4} \mathrm{We}$ hypothesized that limited ability to activate effector mechanisms might protect against immune complex (IC) immunopathology. Here we show that IgG1-deficient $\left(\gamma 1^{-}\right)$mice, ${ }^{5}$ immunized with a potent antigen (Ag), develop lethal renal disease soon after they begin to produce $\mathrm{Ag}$-specific antibody (Ab), while similarly immunized wild-type (WT) mice remain healthy. Surprisingly, renal disease in this model is complement- and FcR-independent and results from IC precipitation in glomerular capillaries, as in some cryoglobulinemic humans. ${ }^{6} \mathrm{IgG} 3$, which self-associates to form large $\mathrm{ICs}^{7,8}$, , accounts for $>97 \%$ of the mouse Ig in this cryoglobulin; furthermore, glomerular disease develops when mice are injected with IgG3 anti-trinitrophenyl (TNP) monoclonal antibody (mAb) followed by a TNPlabeled protein. Renal disease is prevented in both active and passive immunization models by $\mathrm{Ag}$-specific IgG1; other isotypes are less potent at preventing disease. These observations demonstrate the adaptive significance of Ig isotypes that poorly activate effector mechanisms, reveal an IC-dependent, complement- and FcR-independent nephrotoxic mechanism, and suggest that isotypes that poorly activate effector mechanisms may be useful for inhibiting IC immunopathology.

Immunization of WT BALB/c or C57BL/6 mice with a potent immunogen, goat anti-mouse $\mathrm{IgD}$ antiserum (GaMD), leads to a large, rapid, predominantly IgG1 Ab response to goat $\operatorname{IgG}$ (GIgG) and the generation of mouse $\mathrm{IgG} 1 / \mathrm{GIgG} \mathrm{ICs}^{9}$, but no noticeable disease. In contrast, GaMD-immunized $\gamma 1^{-}$BALB/c and C57BL/6 mice develop renal disease characterized by increased urinary protein, leukocyte esterase (LE) and erythrocytes (blood), starting 6-7 days post-immunization, as well as increased blood concentration of urea (BUN), and decreased serum albumin, with anasarca (subcutaneous edema) and peritoneal effusion (Fig. 1a-e and Extended Data Fig. 1a). Kidney color in these mice changes from red-brown to yellow, reflecting dramatically decreased perfusion (Fig. 1f). Microscopically, glomerular capillaries contain IgG and complement deposits, but few inflammatory cells (Figs. 1g and Extended Data Fig. $1 b$ and c). The microscopic damage is initially observed 6-7 days after GaMD immunization and is followed by disruption of glomerular structure and development of fibrosis (Fig. 1g and Extended Data Fig. 1c). Because no other organ damage was observed (not shown), it is likely that renal insufficiency caused the death of $60-80 \%$ of $\gamma 11^{-}$mice by day 16-22 post-immunization (Fig. 1h).

Lack of the normally dominant IgG1 response in GaMD-immunized $\gamma 1^{-}$mice was accompanied by increased production of IgG3, IgM, and in some experiments, $\operatorname{IgG} 2 \mathrm{a}$ (Fig. 2a and Extended Data Fig. 2a). Because these isotypes, unlike IgG1, strongly activate complement and IgG2a potently activates all stimulatory IgGFcRs, ${ }^{1-3}$ we expected renal disease in $\gamma 1^{-}$mice to be complement- and possibly FcR-dependent. However, severe renal disease still developed in GaMD-immunized $\gamma 1^{-}$mice that lacked both $\mathrm{C} 3$, the complement component that is generally required for all complement activation pathways, ${ }^{2}$ and $\mathrm{FcR} \gamma-$ chain $\left(\mathrm{FcR} \gamma\right.$ ), a required component of all stimulatory FcRs in mice ${ }^{10}$ (Figs. $2 \mathrm{~b}$ and $\mathrm{c}$ and Extended Data Fig. 2b). This was true even when these mice were also treated with C5a antagonists (Extended Data Fig. 3). Inhibition of IgG2a production with anti-IFN- $\gamma \mathrm{mAb}^{11}$ also failed to suppress kidney disease (Extended Data Fig. 2c and d). Additional studies eliminated the possibilities that renal disease in $\gamma 1^{-}$mice results from persistence of 
circulating $\mathrm{Ag}$ or a decreased ratio of Ig to $\mathrm{Ag}$ that might form more inflammatory ICs (Extended Data Fig. 4).

These observations suggested that GaMD-induced kidney disease might be caused by a qualitative change in the ICs in immunized $\gamma 1^{-}$mice. Consistent with this, IgG3, the dominant isotype produced in these mice, generates large ICs by self-associating through $\mathrm{Fc}-\mathrm{Fc}$ interactions ${ }^{7,8}$; these large ICs tend to reversibly precipitate at reduced temperature (i.e.; they are cryoglobulins) and at increased concentration (which occurs as plasma is ultrafiltered in glomeruli). Indeed, large cryoglobulin concentrations were found in plasma from GaMD-immunized $\gamma 1^{-}$, but not WT mice (Fig. 2d); cryoglobulin analysis demonstrated that IgG3 was the dominant mouse Ig constituent, although they also contained IgM (Fig. 2e). In keeping with this, deposits within glomerular capillaries were rich in IgG3 (Fig. 2f). A dominant role for IgM in this kidney disease model is unlikely because glomerular IgM, unlike glomerular IgG3, does not persist (Extended Data Fig. 5); severe disease still develops in immunized mice deficient in both IgG1 and J chain (Extended Data Fig. 6), which produce little pentameric $\operatorname{IgM} ;{ }^{12}$ and mice that lack activation-induced cytidine deaminase (AID) and consequently secrete only IgM do not develop kidney disease following GaMD immunization (data not shown).

A passive immunization model was used to further test the hypothesis that renal disease can be caused by IgG3/Ag IC precipitation in glomerular capillaries. WT BALB/c mice were injected simultaneously with IgG3 anti-TNP mAb i.v.and TNP-goat serum (TNP-GIgG) s.c.on days 0 and 1 . These mice developed increased BUN, urine protein, LE, and blood, and large deposits of amorphous material in glomerular capillaries on day 2 (Fig. 3a-c and Extended Data Fig. 7a). Similar lesions developed in similarly treated C3-deficient mice, (Fig. 3d and Extended Data Fig. 7b) and FcR $\gamma$-deficient mice, as well as in C57BL/6 mice and in BALB/c WT mice when TNP-BSA was substituted for TNP-GIgG (not shown). WT mice injected with TNP-GIgG plus IgG1, IgG2a, or IgG2b anti-TNP mAb failed to develop renal disease (Fig. 3a and Extended Data Fig. 7a). None of the mAbs induced disease when injected without TNP (Fig. 3b and data not shown).

The unique pathogenicity of $\operatorname{IgG} 3$ raised the possibility that the other IgG isotypes might be able to inhibit IgG3-mediated disease. Consistent with this, GaMD induced only transient renal disease in $\gamma 1^{+/-}$mice, which produced $\sim 50 \%$ as much IgG1 as WT $\left(\gamma 1^{+/+}\right)$mice, but similar IgG3 as $\gamma 1^{-/-}$mice (Extended Data Fig. 8). Similarly, development of proteinuria, hypoalbuminemia and azotemia in GaMD-immunized $\gamma 1^{-/-}$mice was suppressed by administration of the IgG1 anti-GIgG-rich serum from GaMD-immunized WT mice (GaMD immune WT serum). This suppression was Ag-specific, because it was not observed with serum from rabbit anti-mouse IgD-immunized WT mice (RaMD immune WT serum) (Figs. $4 a$ and $b$ ). Disease suppression by GaMD immune WT serum required initiation of treatment by day 5 after GaMD immunization (Extended Data Fig. 9a), when immunized mice first secrete IgG anti-GIgG. Importantly, injection of GaMD immune WT serum starting 4-5 days after GaMD immunization suppressed renal disease in $\gamma 1^{-}$mice without decreasing serum IgM, IgG2a or IgG3 levels and only modestly decreased production of any isotype by cultured spleen cells (Fig. 4c and Extended Data Fig. 9b). Thus, IgG1 primarily suppresses renal disease in our model by competing with IgG3 for Ag epitopes and/or changing the 
solubility of ICs rather than by decreasing IgG3 secretion; and the increased IgG3 secretion by GaMD-immunized $\gamma 1^{-}$mice results from blocked isotype switching rather than from a lack of IgG1.

Consistent with our conclusion that IgG1 suppresses IgG3-induced renal disease by competing with IgG3 for Ag binding and/or changing IC solubility, IgG1 anti-TNP mAb suppressed glomerular IgG3 deposition and disordered renal function when mice were injected with IgG3 anti-TNP mAb plus TNP-BSA or TNP-goat serum (Fig. 4d, e and Extended Data Fig. 10). Very little IgG1 was found in the glomeruli of mice injected with both isotypes (Extended Data Fig. 10b), suggesting that the presence of IgG1 in an IC with $\mathrm{IgG} 3$ prevents glomerular IC deposition and/or increases its clearance. IgG1 suppression of IgG3-associated renal disease did not depend on $\mathrm{C} 3$ or Fc $\gamma \mathrm{RIIB}$ (Fig. 4d and e and Extended Data Fig. 7b, c) and isotype control mouse IgG1 mAb had no effect on IgG3mediated disease (data not shown). IgG1 anti-TNP was more potent than IgG2a anti-TNP, and $\mathrm{IgG} 2 \mathrm{a}$ anti-TNP more potent than IgG2b anti-TNP, at preventing IgG3-mediated disease (Fig. 4f and Extended Data Fig. 7d), even though isotype switch variants of IgG1, IgG2a and IgG2b were used that had identical Ag binding V regions, ${ }^{13}$ avidity for TNP (Extended Data Fig. 7e), non-specific binding to IgG3 (Extended Data Fig. 7f) and similar non-specific binding to themselves (Extended Data Fig. 7g). Preferential inhibition by IgG1 over IgG2a and $\mathrm{IgG} 2 \mathrm{~b}$ was also seen in studies with a second set of $\mathrm{mAbs}$ that were not switch variants (not shown).

The increased ability of IgG1 to inhibit IgG3-mediated renal disease may be a consequence of its short hinge region length and consequent low segmental flexibility. This may limit IC formation by decreasing IgG1's ability to bind bivalently to a ligand and increasing the likelihood that it will sterically block binding of IgG3, ${ }^{14}, 15$ which could separate IgG3 molecules sufficiently to inhibit their self-association. Consistent with this possibility, IgG2a, which has hinge region length and segmental flexibility intermediate between IgG1 and $\operatorname{IgG} 2 \mathrm{~b}^{14}$, had an intermediate ability to suppress IgG3-mediated renal disease (Fig. 4f and Extended Data Fig. 7d). Thus, IgG1 may limit Ab-mediated disease in our model by suppressing the formation of ICs that become insoluble when they are concentrated by glomerular filtration. We cannot, however, eliminate the possibility that the addition of IgG1 to IgG3/Ag ICs facilitates their elimination by the reticulo-endothelial system, which could limit nephrotoxicity.

Our observations make two important points: First, we show that ICs can destroy kidney function by precipitating in glomerular capillaries, even in the absence of complement and FcR activation. The rapidity of capillary obstruction and the lack of an anaphylatoxin gradient in our model, as well as the ability of complement to increase IC solubility and elimination ${ }^{16}$, may explain the failure of complement to exacerbate disease despite its deposition in glomeruli. Secondly, we show that Ig isotypes that activate effector mechanisms poorly protect against disease caused by more proinflammatory isotypes. In this regard, isotypes such as mouse IgG1 and human IgG4 appear to act like partial agonists, which can cause immunopathology under some conditions, but prevent it by blocking the effects of other, more proinflammatory isotypes, in other circumstances. Indeed, functional similarities between mouse IgG1 and human IgG4 suggest that our observations in mice are 
human-applicable. Mouse IgG1-mediated protection against IC deposition in our model is probably facilitated by its short hinge region, which limits Ag crosslinking by decreasing segmental flexibility ${ }^{14}$. Human IgG4 is likely to have even greater ability to suppress IC development because, in addition to its short hinge region ${ }^{14}$, its labile inter-heavy chain disulfide bond allows it to dissociate into univalent half molecules ${ }^{17}$.

Similar abilities of mouse IgG1 and human IgG4 to suppress disease caused by other isotypes may extend further. While not shown in this paper, our preliminary observations, with additional collaborators, demonstrate that the absence of IgG1 promotes the development and severity of complement- and $\mathrm{Fc} \gamma \mathrm{R}$-mediated diseases in mice, including collagen-induced arthritis and experimental myasthenia gravis. Thus, mouse IgG1 likely suppresses disease mediated by complement and $\mathrm{Fc} \gamma \mathrm{Rs}$, as well as disease mediated by excessive intravascular formation of insoluble ICs. The inability of human IgG4 to activate complement ${ }^{2,3}$ and its poor binding to $\mathrm{Fc} \gamma \mathrm{Rs}^{4}$ suggest that it can similarly limits organ damage in complement- and Fc $\gamma \mathrm{R}$-mediated diseases. These considerations raise the possibility of using human IgG4 Abs to suppress autoimmune and IC disorders that are mediated by other isotypes, an approach that might be amplified by making IgG4 Abs even more immunosuppressive by increasing their sialylation ${ }^{18}$, galactosylation ${ }^{19}$, and/or affinity for $\mathrm{Fc} \gamma \mathrm{RIIB}{ }^{20}$.

\section{Methods}

\section{Mice}

All mice were bred and maintained in the SPF facility at the Cincinnati Children's Research Foundation and all experiments were done with the approval of and in accordance with regulatory guidelines and standards set by the Institutional Animal Care and Use Committee of Cincinnati Children's Hospital Medical Center. Male and female mice were used between the ages of 8 and 20 weeks. BALB/c and/or C57BL/6 background $\gamma 1$-deficient mice ${ }^{5}$, FcR $\gamma$ deficient (Taconic, Hudson, NY), C3-deficient mice (a gift from Dr. Marsha Wills-Karp, Cincinnati Children's Hospital, Cincinnati, OH), J-chain deficient mice (a gift of Dr. Dennis Metzger, Albany Medical College, USA), Fc $\gamma$ RIIB-deficient, AID-deficient (a gift of Dr. M. Muramatsu, Kyoto University, Kyoto, Japan) ${ }^{21}$ and WT control mice were bred in our colony. Double and triple gene-deficient mice, made by crossbreeding the single genedeficient mice, were typed by PCR. Typing for $\gamma 1$ and C3 deficiency was confirmed by gel double diffusion assay of serum. WT littermates of the double and triple gene-deficient mice were used as controls. Mice of the appropriate genotype were randomly assigned to groups, but a specific randomization program was not used. Studies were not blinded.

\section{Active model for induction of IC renal disease}

Mice were injected s.c. with $0.2 \mathrm{ml}(\mathrm{BALB} / \mathrm{c})$ or $0.4 \mathrm{ml}(\mathrm{C} 57 \mathrm{BL} / 6)$ of GaMD on day 0. In some experiments mice were also injected i.p. daily with pooled day 12 serum from GaMD or RaMD immunized WT mice (GaMD immune WT serum and RaMD immune WT serum, respectively). Spontaneously micturated urine was collected from mice on specific days and assayed for protein, LE and blood content by urine dipstick. Serum was collected by tail 
vein puncture and kidneys were preserved in formalin or gluteraldehyde or frozen in OCT for histologic evaluation.

\section{Passive model for IC induction of renal disease}

Mice were simultaneously injected with mouse IgG3 anti-TNP mAb i.v.and TNP-goat serum or TNP-BSA s.c. on days 0 and 1. Some mice also received mouse IgG1, IgG2a or $\operatorname{IgG} 2 b$ anti-TNP mAb isotype switch variants or in some cases non-switch variant mAbs i.v.on days 0 and 1 .

\section{Reagents}

Hybridomas were obtained from the following sources: 9A6 (mouse IgG3 anti-TNP mAb), a gift from Shozo Izui ${ }^{22}$; 1B7.11 (mouse IgG1 anti-TNP mAb), from the American Type Culture Collection (Rockville, MD); HY1.2 and C1040 (mouse IgG2a anti-TNP mAbs) and GORK (mouse IgG2b anti-TNP mAb), a gift from Brigitta Heyman; switch variant mouse IgG1, IgG2a and IgG2b anti-TNP mAbs, a gift from Mike Robson ${ }^{23}$ and XMG-6 (rat IgG1 anti-mouse IFN- $\gamma)^{24}$ from DNAX, Palo Alto, CA. A hybridoma that secretes mouse IgG1 anti-FITC $\mathrm{mAb}$ was produced in house. Hybridomas were grown as ascites in Pristaneprimed athymic nude mice and mAbs were purified from ascites by ammonium sulfate precipitation (25\%-50\% for all IgGs except 20\%-30\% for IgG3), followed by DE-52 cation exchange chromatography for the IgG isotypes. IgG2a anti-TNP mAb was also purchased from Bio X Cell (Lebanon, NH). GaMD and RaMD antisera were made as described ${ }^{25}$. Mouse hyperimmune antisera to goat (GaMD immune WT serum) and rabbit (RaMD immune WT serum) were made by injecting WT mice s.c.every 14 days for several injections with GaMD or RaMD, respectively and pooling serum collected 10-12 d after each immunization. Non-immune mouse serum was collected by tail vein bleeding from untreated BALB/c or C57BL/6 WT mice and pooled. The C5aR antagonists, JPE $1275^{26}$ (a gift from John Lambris, U of Penn, Philadelphia, PA) and A8871-73 ${ }^{27}$, were injected as 20 $\mu \mathrm{g}$ or $10 \mu \mathrm{M}$ doses, respectively, i.p. every $12 \mathrm{hrs}$ starting on $\mathrm{d} 4$ and ending on $\mathrm{d} 8$ after GaMD immunization.

\section{Urine and serum measurements}

Urine protein, LE and blood levels were measured on fresh, freely excreted urine using Multistik 10 (Becton-Dickson). Measurements were on a colorimetric scale, ranging from 0 to 4 for protein and 0 to 3 for LE and blood, as per manufacturers' instructions. Serum albumin and BUN were measured using a Beckman DXC (Brea, CA) courtesy of Mr. Robert Louderbeck, Veterans Administration Medical Center, Cincinnati, Ohio. Serum, splenic supernatants and re-suspended cryoglobulin pellets were analyzed for total and GIgG-specific IgG1, IgG2a/c, IgG2b, IgG3, IgE, IgA and IgM content, using standard sandwich ELISA with paired anti-Ig isotype mAbs for each Ig isotype (BD-Pharmingen and eBioscience). Sera, splenic supernatants and re-suspended cryoglobulin solutions were titered for GIgG-specific Ab levels by ELISA, as previously described ${ }^{25}$, using wells coated with $5 \mu \mathrm{g} / \mathrm{ml}$ of goat IgG. Gel double diffusion was used to identify mouse $\mathrm{IgG1}$, mouse C3 and GIgG in mouse serum with Abs purchased from Bethyl. 


\section{TNP-goat serum and TNP-BSA}

Goat serum or BSA were conjugated to TNP as previously described ${ }^{28}$.

\section{Immunofluorescence microscopy}

Kidneys were harvested from mice and immediately placed in OCT and snap frozen in liquid nitrogen. OCT-embedded kidneys were stored at $-80^{\circ} \mathrm{C}$. Frozen tissue sections were cut, mounted on glass slides, fixed in acetone and air-dried. After rehydration and blocking, immunofluorescence microscopy was performed with FITC-labeled anti-C3 and anti-mouse IgG antibodies (ICN biomedicals Inc./Cappel, Aurora, Ohio). After washing, coverslips were applied to slides after addition of anti-fade medium that contained DAPI (Prolong Gold; Invitrogen Corp., Carlsbad CA). Slides were assessed microscopically and photographed at an original magnification of 400X using an RT Slider digital camera (Diagnostic Instruments Inc., Sterling Heights, MI) mounted on an E600 fluorescent microscope (Nikon Instruments, Melville, NY).

\section{Immunostaining microscopy}

Kidneys were harvested from mice and immediately placed in formalin for a minimum of 3 days before embedding in paraffin. For IgG3 staining, de-paraffinised sections were incubated with goat anti-mouse IgG3 antibody (Jackson ImmunoResearch Laboratories, West Grove, PA) for $1 \mathrm{hr}$, then incubated for $12 \mathrm{~min}$ with biotin-donkey anti-goat IgG antibody (Jackson ImmunoResearch Laboratories) and visualized with an iVIEW Plus Detection Kit (Ventana Medical Systems, Tucson, AZ). Staining for IgG1 was performed with a rabbit anti-mouse IgG1 antibody (Novus Biologicals, Littleton, CO), followed by biotin-donkey anti-rabbit antibody (Jackson ImmunoResearch Laboratories). All antibodies were used at 1:100 dilutions and all staining was performed with a Discovery XT (Ventana Medical Systems).

\section{Quantitation of splenic Ig production}

Spleens were diced into 1-2 mm cubes, washed in ice cold PBS, then transferred to a Petri dish with $5 \mathrm{ml}$ of RPMI medium 1640 supplemented with fetal bovine serum, penicillin, gentamicin, HEPES, sodium pyruvate, essential amino acids and 2-mercaptoethanol and cultured at $37^{\circ} \mathrm{C}, 5 \% \mathrm{CO}_{2}$ for $24 \mathrm{hrs}$. Supernatants were collected, separated into aliquots, frozen and stored at $-80^{\circ} \mathrm{C}$ until analyzed.

\section{Cryoprecipitant collection}

Blood was collected in a polystyrene centrifuge tube and immediately incubated for $4 \mathrm{hrs}$ at $37^{\circ} \mathrm{C}$. The tube was centrifuged and solid material was removed. Sera were incubated at $4^{\circ} \mathrm{C}$ for 7 days. Precipitates were obtained by centrifugation, washed 3 times in ice-cold saline, then re-suspended in a volume of saline equal to that of the initial serum sample and heated to $37^{\circ} \mathrm{C}$ for $2 \mathrm{hrs}$ to dissolve cryoprecipitates. Samples were then re-centrifuged at room temperature and supernatants were collected. 


\section{Anti-TNP mAb ELISA}

For avidity measurement ELISA plates were coated with $10 \mu \mathrm{g}$ TNP-OVA $/ \mathrm{ml}$ overnight followed by varying concentrations of the mAbs. This was followed by HRP- or biotinlabeled anti-mouse Ig isotype-specific mAb purchased from BD bioscience, streptavidinHRP if needed and SuperSignal ELISA substrate from Pierce (Cheshire, United Kingdom). For IgG3 binding or self-association measurement, ELISA plates were coated with $10 \mu \mathrm{g}$ mouse IgG1, IgG2a, IgG2b or IgG3 anti-TNP $\mathrm{mAb} / \mathrm{ml}$ overnight followed by varying concentrations of biotin-labeled mouse IgG1, IgG2a, IgG2b or IgG3 anti-TNP mAbs. This was followed by streptavidin-HRP and SuperSignal substrate from Pierce.

\section{Statistics}

The non-parametric Mann-Whitney 2-tailed t test (GraphPad Prism 5.0; GraphPad Software, La Jolla, CA) was used to compare Ig levels, BUN and albumin concentrations between different groups of mice. A P value $<0.05$ was considered significant. A more complex test was used to compare the multiple samples in Fig. $4 \mathrm{f}$ and Extended Data Fig. 7d (see figure legend for details).

Sample size was calculated with a tool for comparing 2 independent samples on the website $<$ http://www.stat.ubc.ca/ rollin/stats/ssize/n2.html>. Sample size calculations for initial studies were based on the assumptions that a one sided test would be used to test the hypothesis that the mean for the normal (usually wild-type) group would be 3 times as large (or one third as large) as the mean for the abnormal (usually $\gamma 1$-deficient) group, that the common standard deviation would be the same size as the smaller mean, that the type I error rate would be 0.05 and that the desired power would be 0.80 . These assumptions suggested a sample size of 4 for each sample. In practice, we often used the results of our initial studies to determine whether this sample size was sufficient to yield the desired power or indicate the larger sample size that would yield a significant result if the trend observed in the initial study predicted the results obtained with the larger sample size. 


\section{Extended Data}

a
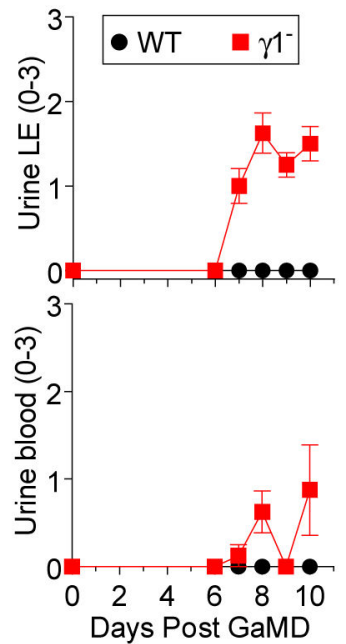

b
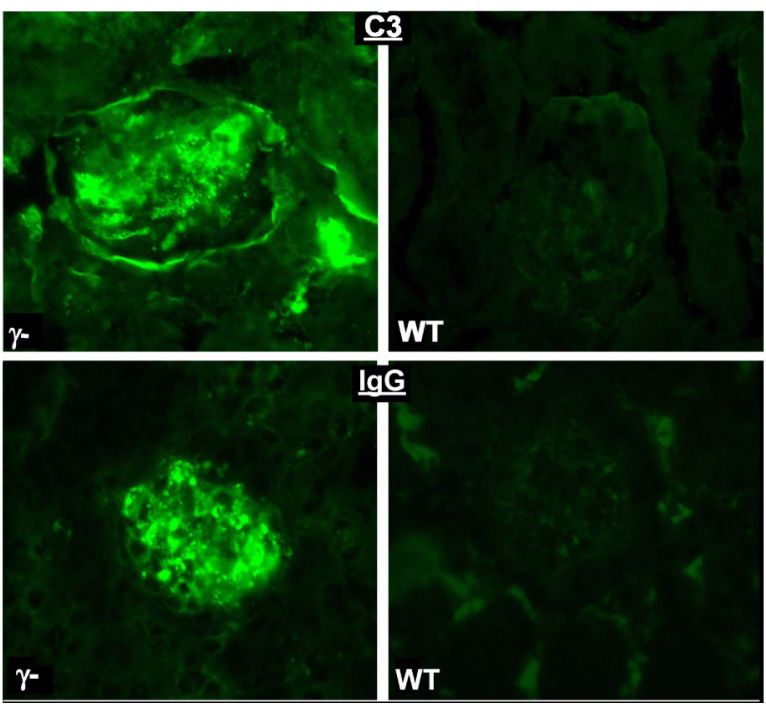

C

GaMD, Day 6

GaMD, Day 7

GaMD, Day 8

GaMD, Day 10

GaMD, Day 11
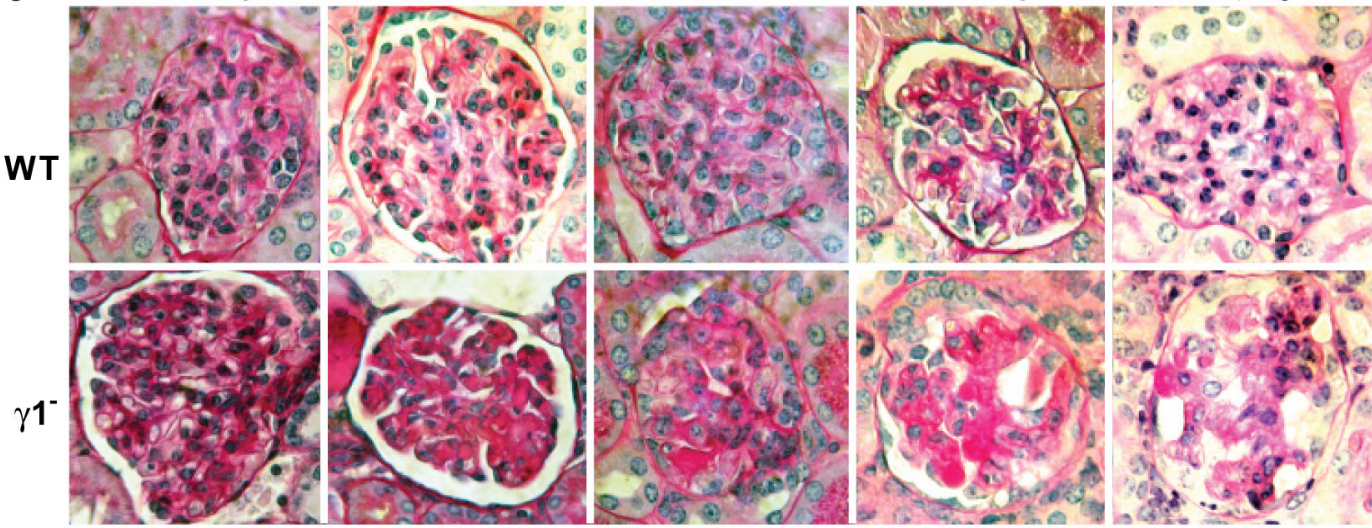

Extended Data Figure 1. GaMD immunization of $\gamma 1^{-}$mice induces renal dysfunction and glomerular deposition of $\mathrm{PAS}^{+}$material that includes IgG and complement

a, WT and $\gamma 1^{-}$mice (4/gp) were immunized with GaMD. Urine LE and blood were obtained. b, Representative photomicrographs of glomeruli stained for C3 (top panels) or total mouse IgG (bottom panels) from WT (right panels) and $\gamma 1^{-/-}$mice (left panels) $12 \mathrm{~d}$ post-GaMD immunization 3 mice/group. c, Deposition of amorphous PAS $^{+}$material in glomeruli of $\gamma 1^{-}$, but not WT begins $\sim 7$ days post GaMD-immunization and leads to glomerular destruction by day 9 . Note the scarcity of inflammatory cells in glomeruli. Representative data of 6 mice/group. 
a $\square \mathrm{WT}+$ control mAb $\bullet \mathrm{WT}+$ anti-IFN- $\gamma \mathrm{mAb} \square \mathrm{\gamma}^{-}+$control mAb $\bullet \mathrm{1}^{-}+$anti-IFN- $\gamma \mathrm{mAb}$
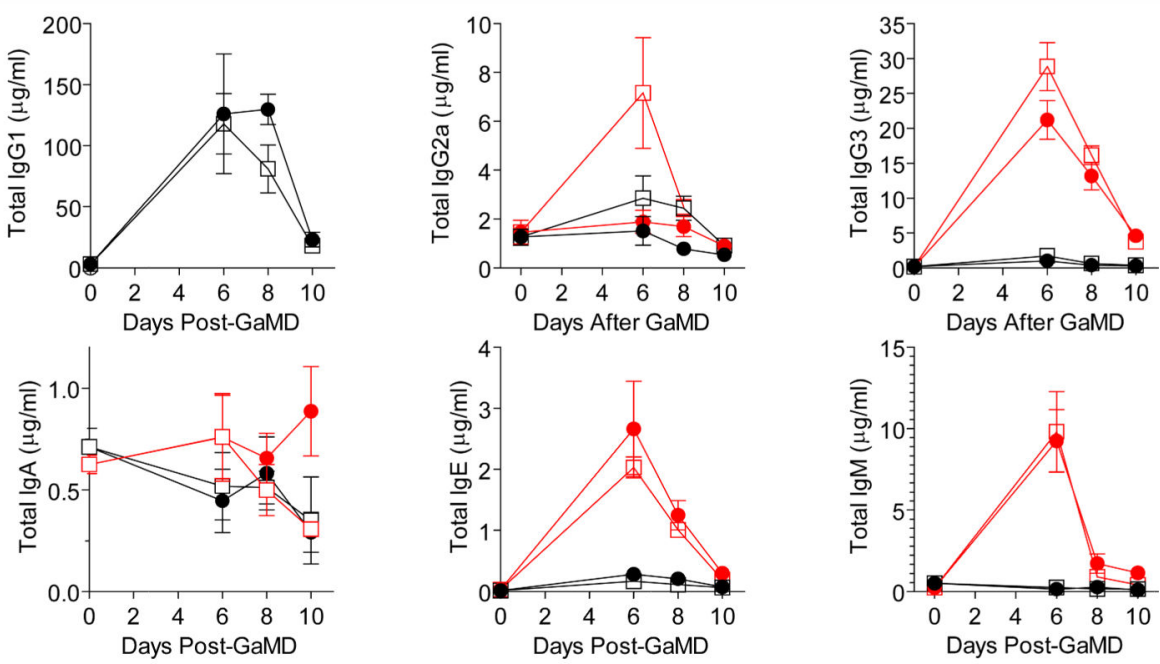

b
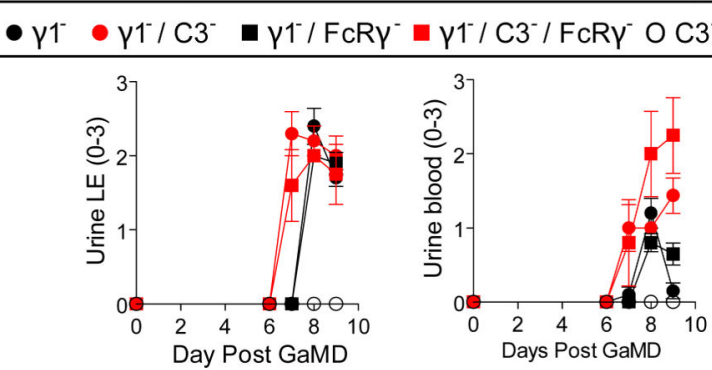

c
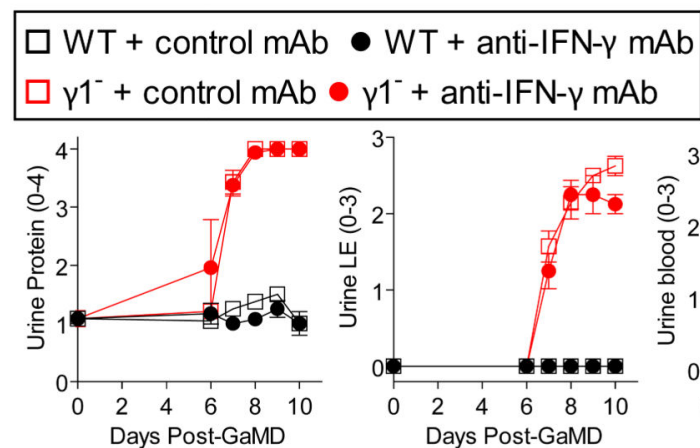

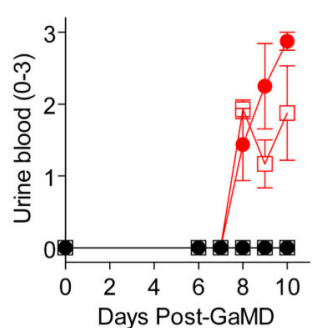

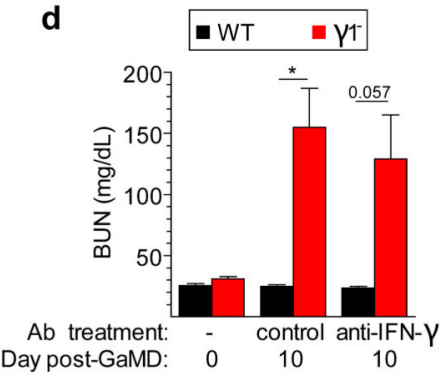

Extended Data Figure 2. The development of kidney disease in GaMD-immunized $\gamma 1^{-}$mice is independent of IFN- $\gamma$, IgG2a, C3 and FCR $\gamma$

$\mathrm{BALB} / \mathrm{c}$ WT and $\gamma 1^{-}$mice (5/gp) were immunized with GaMD on $\mathrm{d} 0$ and injected with $1 \mathrm{mg}$ of either anti-IFN- $\gamma$ or control mAb on days 0 and 5. a, Total levels of all Ig isotypes were determined in $24 \mathrm{hr}$ culture supernatants of spleen cells harvested on days shown. $\mathbf{b}$, GaMDimmunized $\gamma 1^{-}, \gamma 1^{-} / \mathrm{FcR} \gamma^{-}, \gamma 1^{-} / \mathrm{C}^{-}, \mathrm{C} 3^{-} / \mathrm{FcR} \gamma^{-}$and $\gamma 1^{-} / \mathrm{C} 3^{-} / \mathrm{Fc} \gamma \mathrm{R}^{-}$mice $(5 / \mathrm{gp})$ had their urine tested for LE and blood on days shown. $\mathbf{c}, \mathbf{d}, \mathrm{BALB} / \mathrm{c}$ WT and $\gamma 1^{-}$mice (5/gp) were immunized with GaMD on $\mathrm{d} 0$ and injected with $1 \mathrm{mg}$ of either anti-IFN- $\gamma$ or control $\mathrm{mAb}$ on days 0 and 5. c, Urine obtained on days indicated was assayed for protein, LE and blood. d, BUN levels were determined prior to and 10 days after GaMD immunization. ${ }^{*} \mathrm{p}<0.05$ 
$\bullet \mathrm{\gamma}^{-} \bullet \mathrm{\gamma}^{-} \mathrm{XC3}^{-} \times \mathrm{FcR}^{-} \quad \square \mathrm{\gamma}^{-} \mathrm{XC3}^{-} \times \mathrm{FcR}^{-}+\mathrm{C} 5 \mathrm{aR}$ antagonist
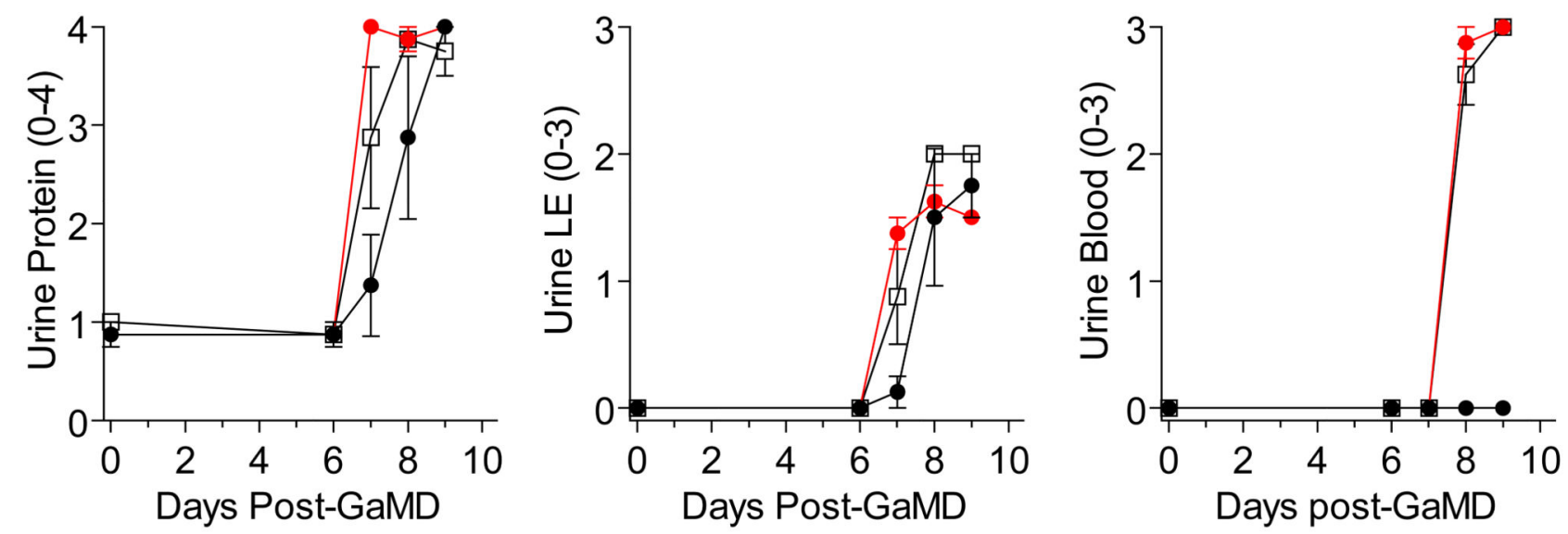

Extended Data Figure 3. Neither complement nor stimulatory FcRs is required for renal disease development in GaMD-immunized $\gamma \mathbf{1}^{-}$mice

Mixed background $\gamma 1^{-}$and $\gamma 1^{-} / \mathrm{C} 3-/ F c R \gamma^{-}$mice (4/gp) were immunized with GaMD $\pm \mathrm{C} 5 \mathrm{aR}$ antagonist. Urinalyses were obtained at baseline and daily starting on day 6 . 
a
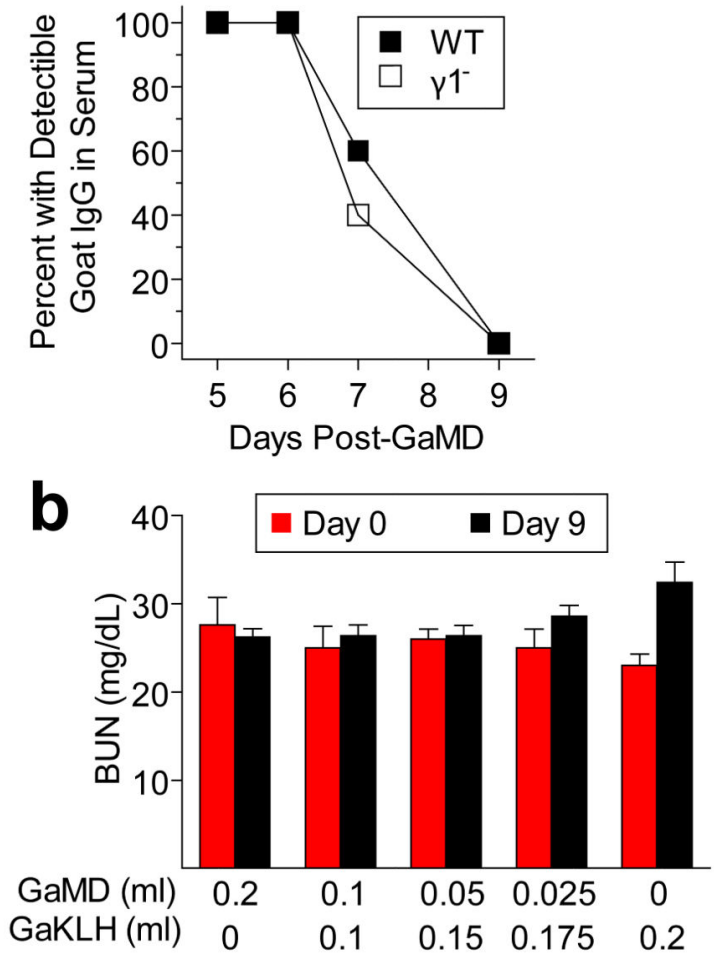

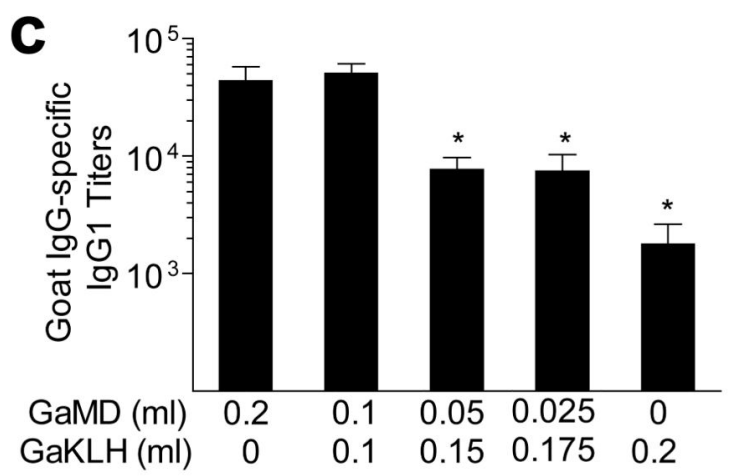

d

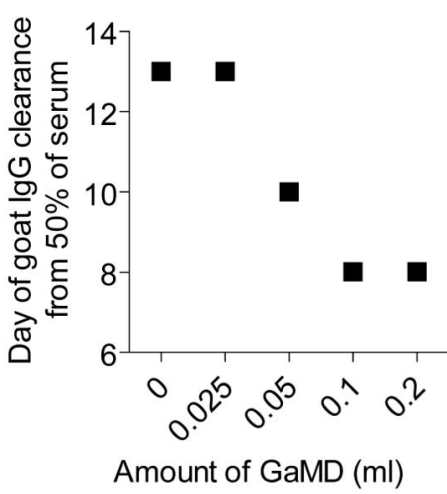

e
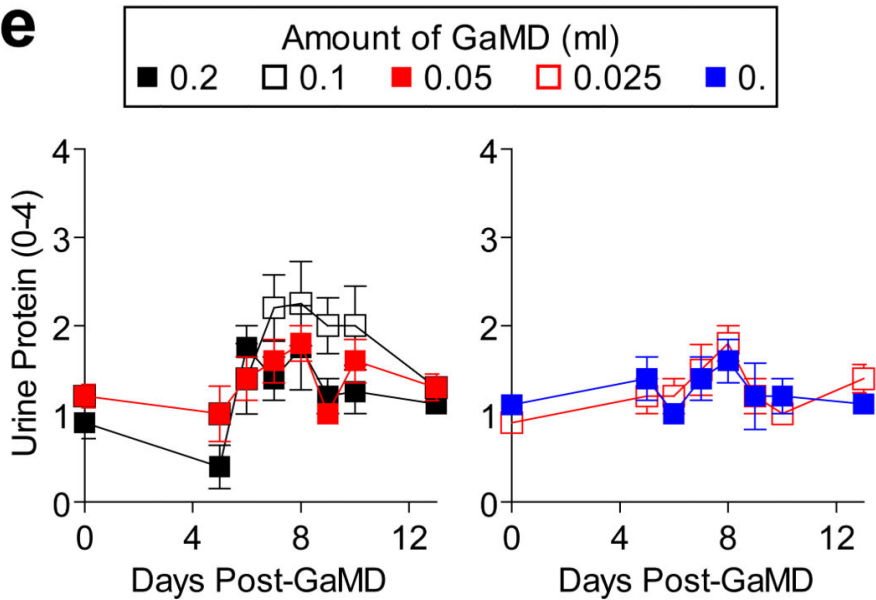

Extended Data Figure 4. Delayed antigen elimination does not account for renal disease in GaMD-immunized $\gamma \mathbf{1}^{-}$mice

a. BALB/c WT and $\gamma 1^{-}$mice (10/gp) were immunized s.c. withGaMD. Sera obtained 5, 6, 7 and 9 days later were evaluated by gel double diffusion for the presence of goat IgG. b-e. BALB/c WT mice (4 or 5/gp) were injected s.c. with a total of $0.2 \mathrm{ml}$ of different mixtures of GaMD and goat anti-KLH antisera. b, c, Mouse sera collected 9d later were assayed for BUN (b) and IgG1 anti-goat IgG Ab (c). d, Sera obtained 6-13d post-immunization were evaluated by gel double diffusion for the presence of goat IgG. e, Urine samples collected 4-12 days post-immunization were analyzed for protein. $* \mathrm{p}<0.05, * * \mathrm{p}<0.005$ 


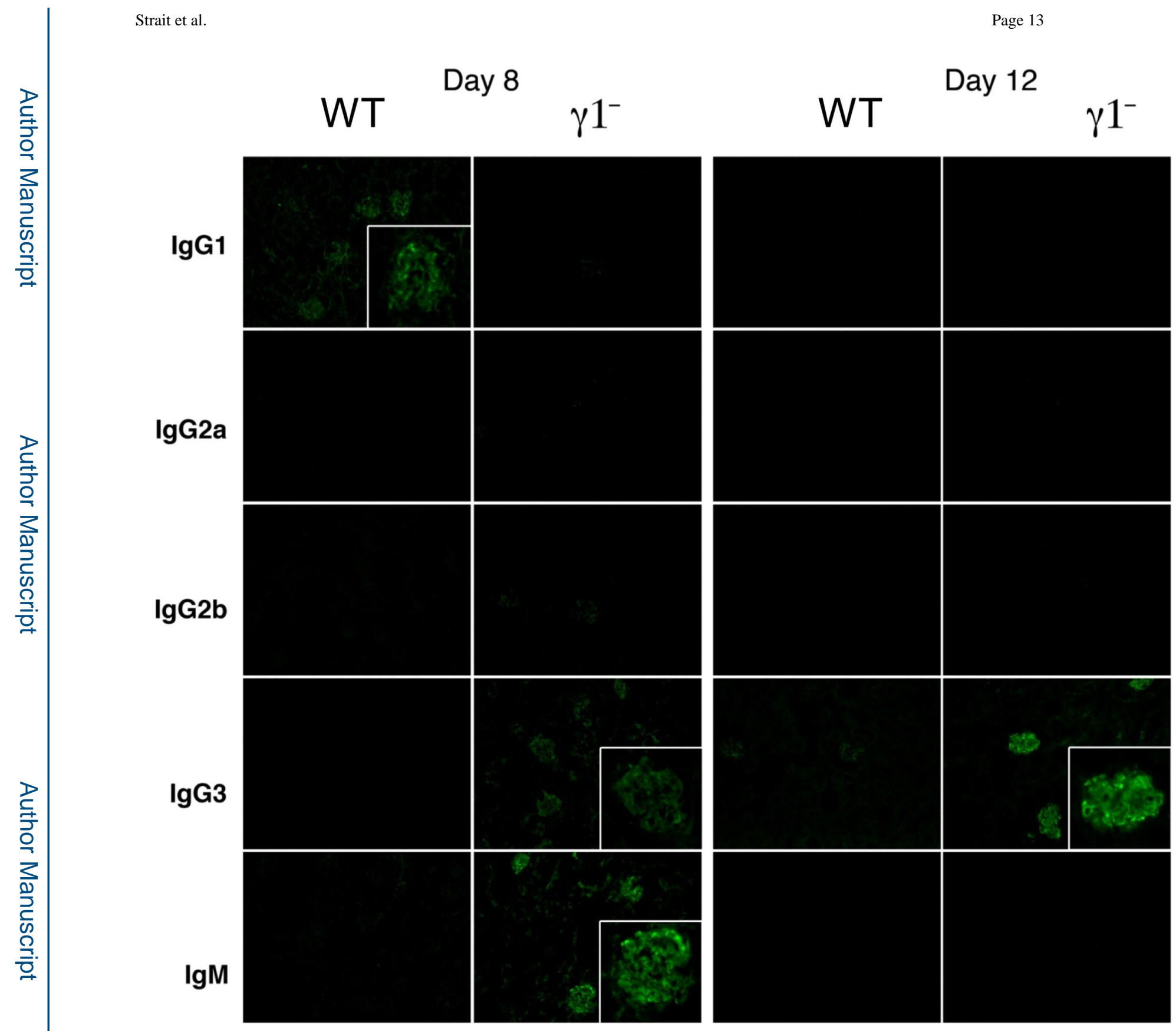

${ }^{* *}$ No staining for any immunoglobulin was seen in the kidney for unimmunized mice

Extended Data Figure 5. IgG3 IC persist and accumulate in the glomeruli of GaMD-immunized $\gamma \mathbf{1}^{-}$

$\mathrm{BALB} / \mathrm{c}$ WT and $\gamma 1^{-}$mice were left untreated or were immunized with GaMD. Kidney sections were stained for mouse IgG1, IgG2a, IgG2b, IgG3 and IgM 8 and 12d later.

Representative photomicrographs from 3 GaMD-immunized mice are shown. Insets show magnified views. No staining was observed with sections from unimmunized mice (not shown). 


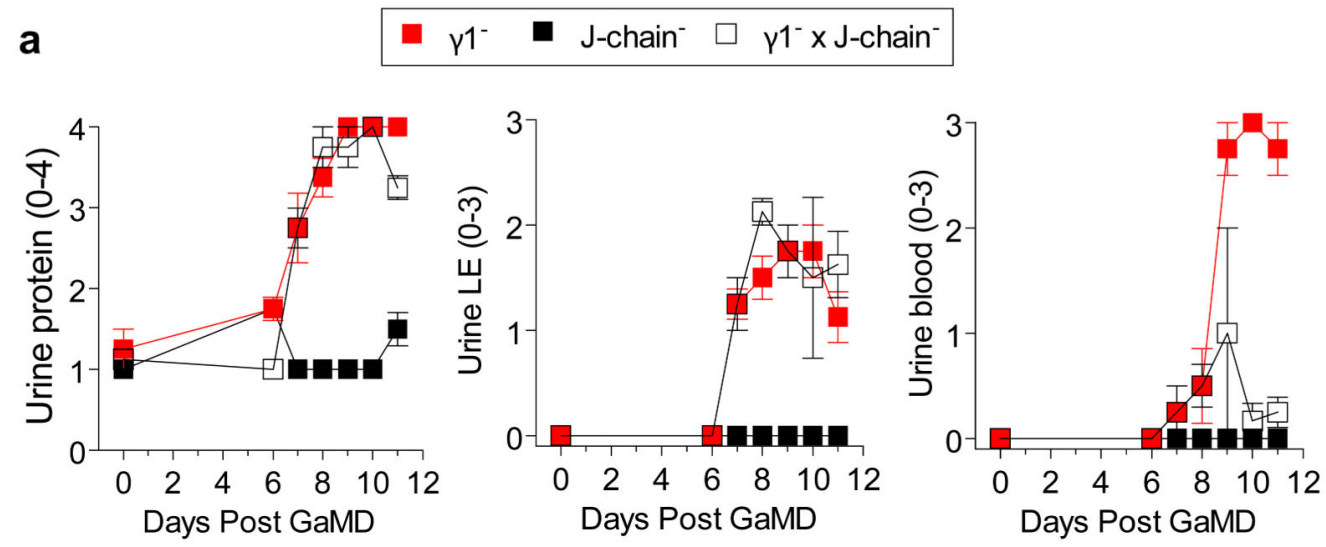

b

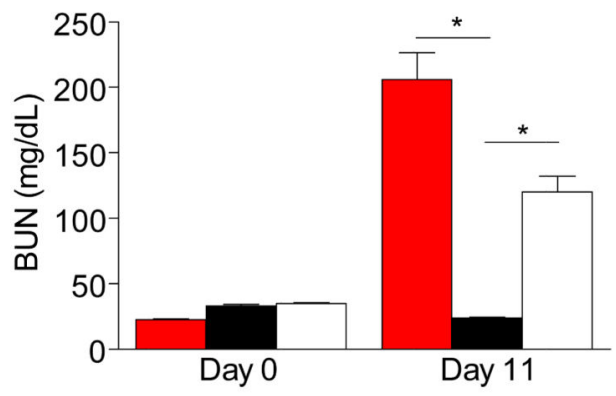

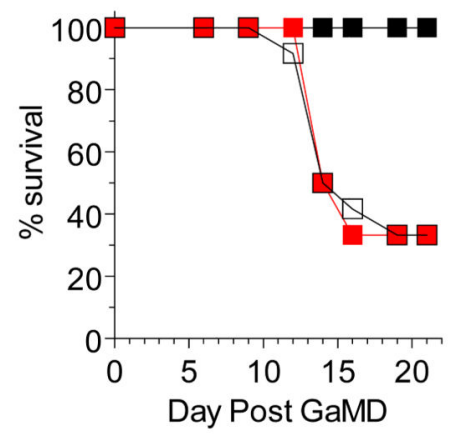

Extended Data Figure 6. Severe renal disease develops in GaMD-immunized $\gamma^{-/ J}$ chain ${ }^{-}$mice $\mathrm{BALB} / \mathrm{c} \gamma 1^{-}$(12 mice), J-chain ${ }^{-}\left(9\right.$ mice) and $\gamma 1^{-} / \mathrm{J}$-chain ${ }^{-}(12$ mice) were injected s.c. with GaMD. a, Urinalysis was performed on indicated days. b, BUN levels on $\mathrm{d} 0$ and 11 . The difference between $\gamma 1^{-}$and $\gamma 1^{-} \times$J-chain- mice was not consistently observed. $\mathbf{c}$, Survival of GaMD-immunized mice. $* \mathrm{p}<0.05$ 
a

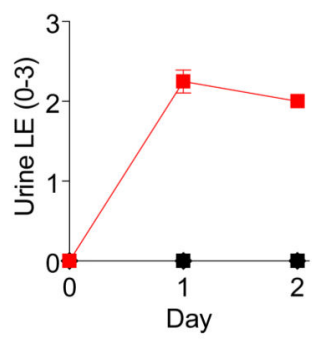

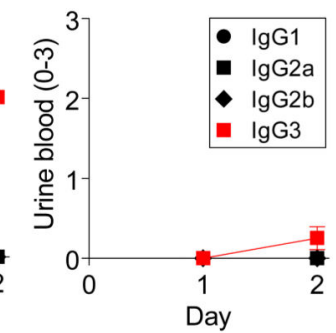

b
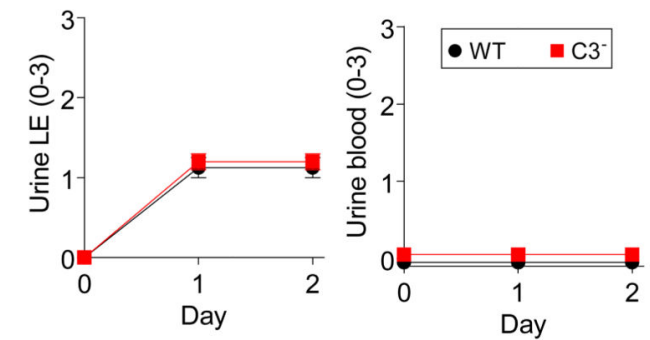

c

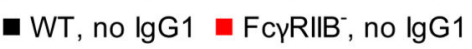

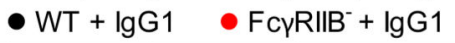
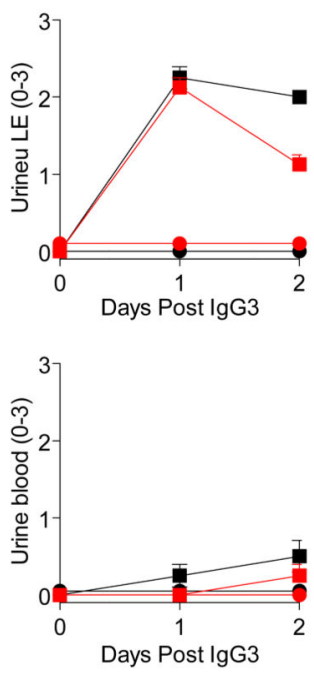

e

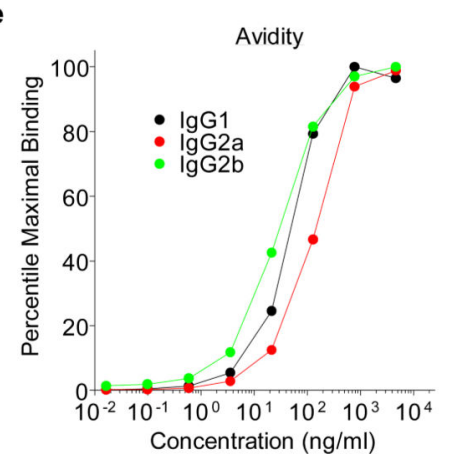

f d $\lg$ G3 alone $\bullet+\lg G 1 \bullet+\lg G 2 a \bullet+\lg G 2 b$
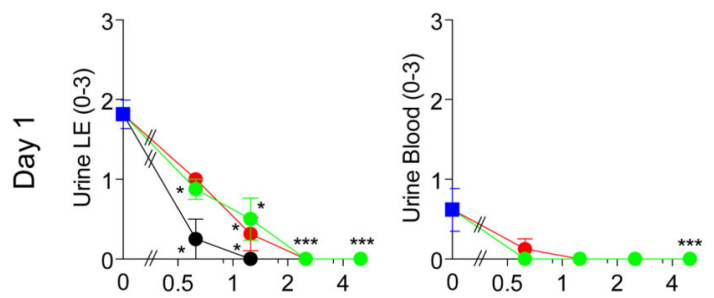

N
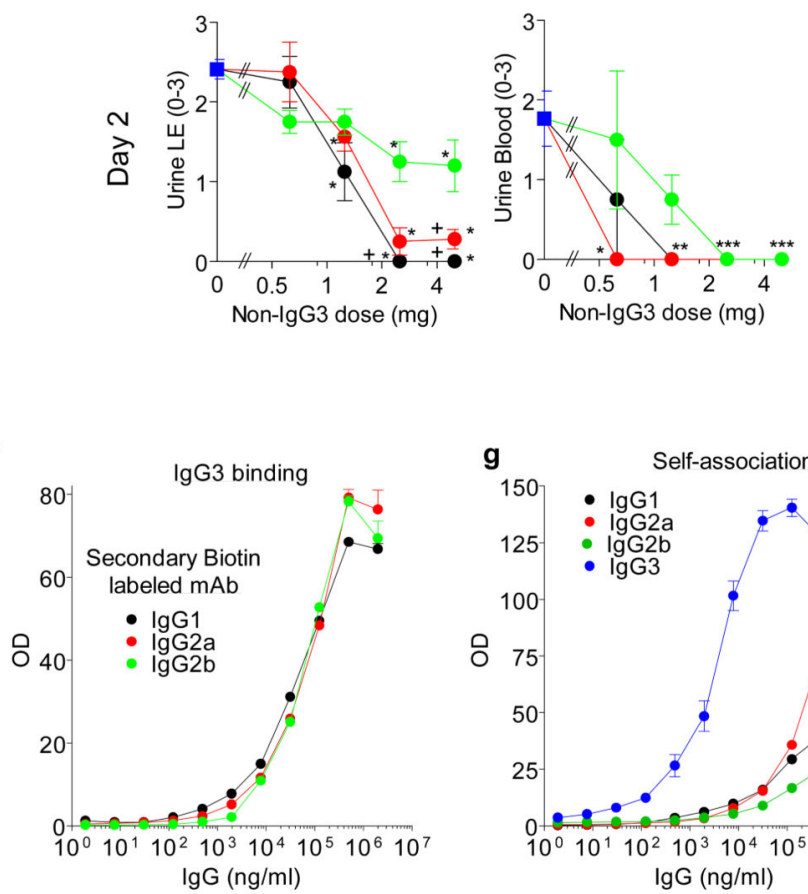

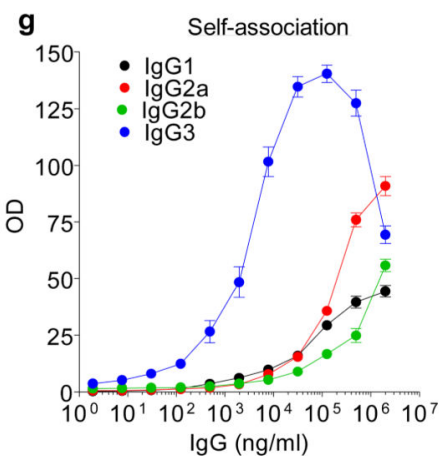

Extended Data Figure 7. IgG1 inhibits IgG3-induced cryoglobulin kidney disease independent of complement and Fc $\gamma$ RIIB and better than IgG2a and IgG2b

a, WT mice (4/gp) were injected i.v. with $4 \mathrm{mg}$ of mouse IgG1, IgG2a, IgG2b, or IgG3 antiTNP mAb and s.c. with $100 \mu \mathrm{l}$ of TNP-goat serum on days 0 and 1 . Urine LE and blood measured prior to injections and on $\mathrm{d} 1$ and $\mathrm{d} 2$. b. Urine LE and blood for BALB/c WT and $\mathrm{C}^{-}{ }^{-}$mice (4/gp) injected i.v. with $4 \mathrm{mg}$ of IgG3 anti-TNP mAb and s.c. with $400 \mu \mathrm{l}$ of TNPgoat serum on $\mathrm{d} 0$ and 1 . c, WT and Fc $\gamma$ RIIB-deficient $\left(\mathrm{Fc}_{\gamma} \mathrm{RIIB}^{-}\right)$mice $(4 / \mathrm{gp})$ were injected s.c. with $100 \mu \mathrm{l}$ of TNP-goat serum and i.v. with $4 \mathrm{mg}$ of IgG3 anti-TNP $\pm 5 \mathrm{mg}$ of $\mathrm{IgG} 1$ 
anti-TNP on $\mathrm{d} 0$ and 1 . Urinalysis on $\mathrm{d} 0,1$ and 2. d, BALB/c mice were injected i.v. with 4 $\mathrm{mg}$ of IgG3 anti-TNP and s.c. with $1.4 \mathrm{mg}$ of TNP-BSA on days 0 and 1 . Some mice were also injected with $0.625,1.25,2.5$, or $5 \mathrm{mg}$ of switch variants of IgG1, IgG2a or IgG2b antiTNP mAbs on $\mathrm{d} 0$ and 1 . Urine protein was determined on $\mathrm{d} 0$ (not shown), $\mathrm{d} 1$ (upper panel) and $\mathrm{d} 2$ (lower panel). Results are pooled from a total of 7 experiments. Group size: IgG3 alone: 19 mice; $0.625 \mathrm{mg}$ of IgG1, IgG2a, or IgG2b: 4 mice; $1.25 \mathrm{mg}$ of IgG1, IgG2a or IgG2b: 8 mice; $2.5 \mathrm{mg}$ of IgG1, IgG2a or IgG2b: 6 mice; $5 \mathrm{mg}$ of IgG1, IgG2a or IgG2b: 8 or 9 mice. The significance of differences between treatment groups was determined as described in the legend to Fig. 4f. \# $\mathrm{p}<0.05$ as compared to IgG2a plus IgG3. $+\mathrm{p}<0.05$ as compared to IgG2b plus IgG3. *p $<0.05$ as compared to IgG3 alone. e, Binding of the Ig isotype switch variants to ELISA wells coated with TNP-BSA, reported as percentage of maximal binding. $\mathbf{f}$, Binding of the Ig isotype switch variants to ELISA wells coated with IgG3 anti-TNP mAb. g, Binding of IgG3 and the Ig isotype switch variants to ELISA wells coated with themselves.

a

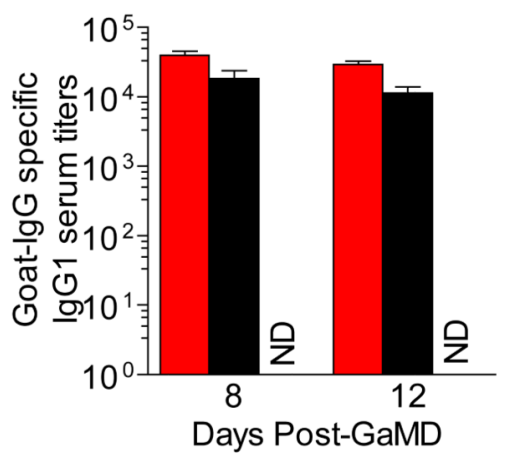

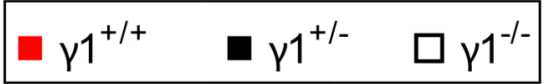
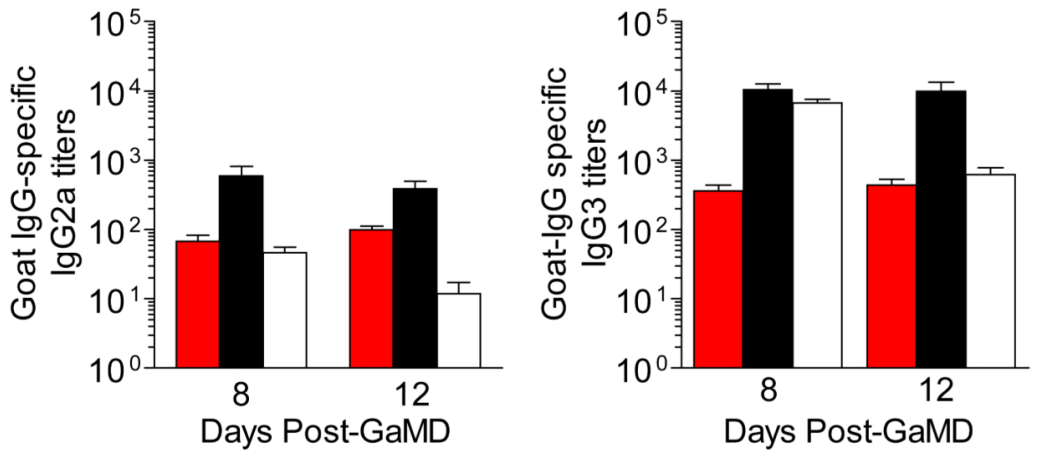

b

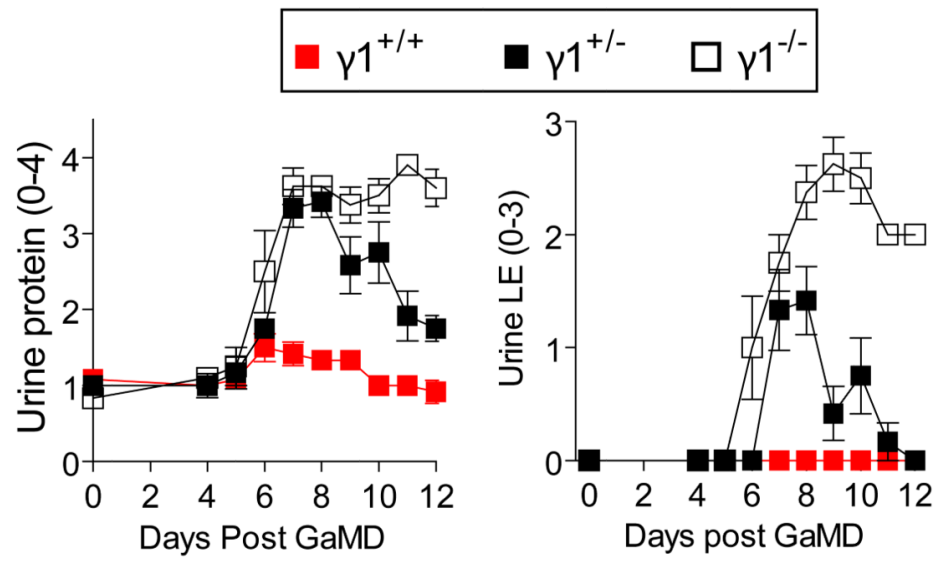

Extended Data Figure 8. GaMD-immunized $\gamma 1^{+/-}$mice generate large IgG3 responses but develop mild renal disease

BALB/c mice homozygous $\left(\gamma 1^{+/+}\right)$, heterozygous $\left(\gamma 1^{+/-}\right)$and null $\left(\gamma 1^{-/-}\right)$for a functional $\gamma 1$ allele (6/gp) were injected s.c. with GaMD. a, Sera were titered for goat IgG-specific IgG1, 
$\operatorname{IgG} 2 \mathrm{a}$ and $\operatorname{IgG} 30,8$ and 12 days later. Day 0 titers were zero for all Ig isotypes (data not shown). b, Urine samples from the same mice were assayed for protein and leukocyte esterase. $\mathrm{ND}=$ none detected.

a

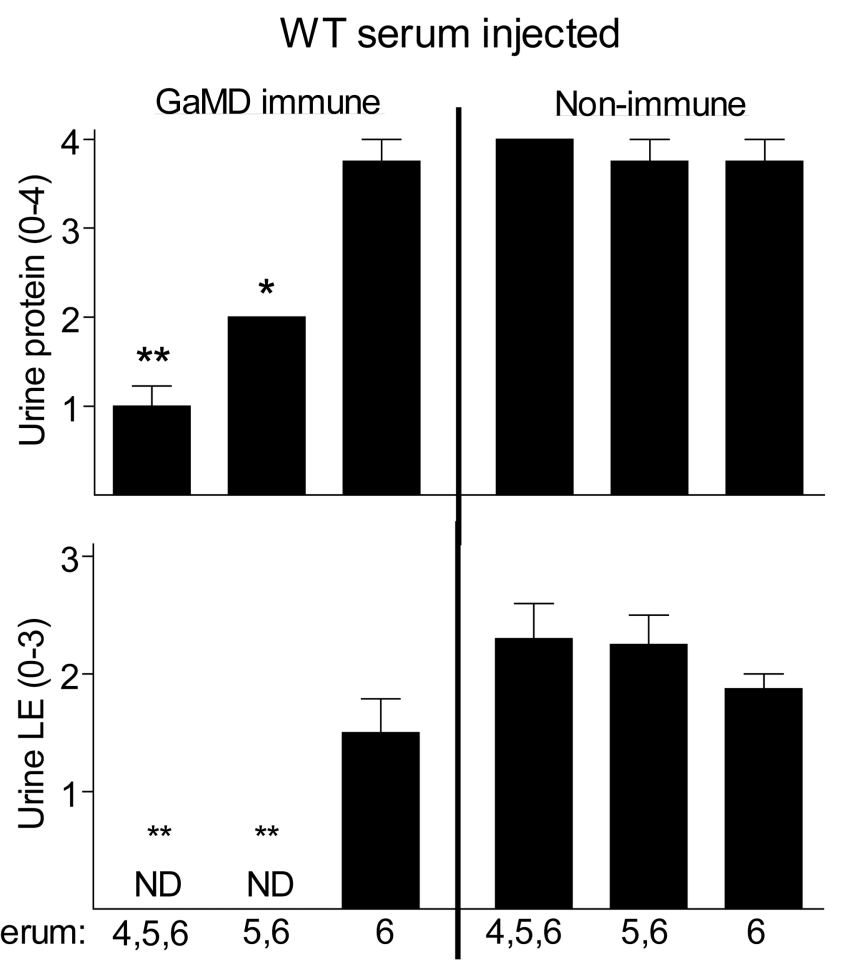

Days injected with serum: \begin{tabular}{lll|llll}
$4,5,6$ & 5,6 & 6 & $4,5,6$ & 5,6 & 6
\end{tabular}

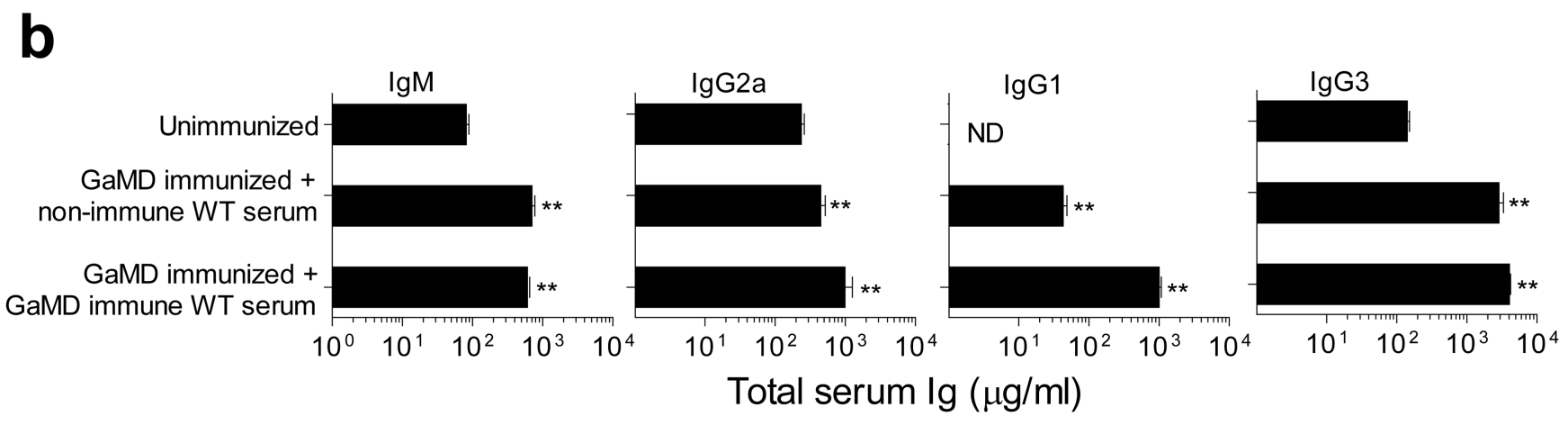

Extended Data Figure 9. GaMD immune serum from WT mice inhibits GaMD-induced renal disease without decreasing other isotypes if injected into GaMD-immunized $\gamma \mathbf{1}^{-}$mice by $5 \mathrm{~d}$ after immunization

a. BALB/c $\gamma 1^{-}$mice ( 4 or $8 / g p$ ) were injected s.c. with GaMD on day 0 and i.p. with $0.5 \mathrm{ml}$ of pooled serum from GaMD-immunized WT mice (GaMD immune WT serum) or unimmunized WT mice (non-immune serum), starting 4, 5, or 6d after GaMD immunization. Day 7 urine samples were analyzed. ND = none detected. $\mathbf{b} . \mathrm{BALB} / \mathrm{c} \gamma \mathbf{1}^{-}$ mice ( 4 or $8 / g p$ ) were injected s.c. with GaMD on day 0 and i.p. with $0.5 \mathrm{ml}$ of pooled serum from GaMD-immunized WT mice (GaMD immune WT serum) or unimmunized WT 
mice (non-immune serum), 5, 6 and $7 \mathrm{~d}$ after GaMD immunization. Sera were assayed for total IgG1, IgG2a, IgM and IgG3 on d0 (unimmunized) and 8d after GaMD immunization. $\mathrm{ND}=$ none detected.For both $\mathbf{a}$ and $\mathbf{b}$, * indicates $\mathrm{p}<0.05$; ** indicates $\mathrm{p}<0.005$ (both as compared to d6 only in a and unimmunized in $\mathbf{b}$.

a

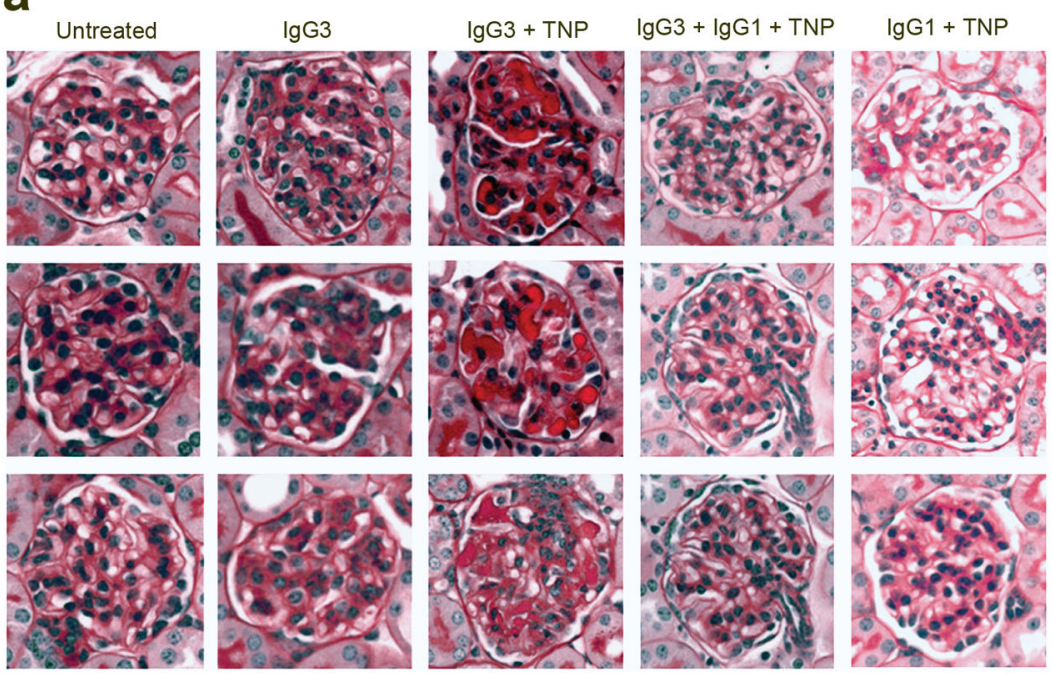

b

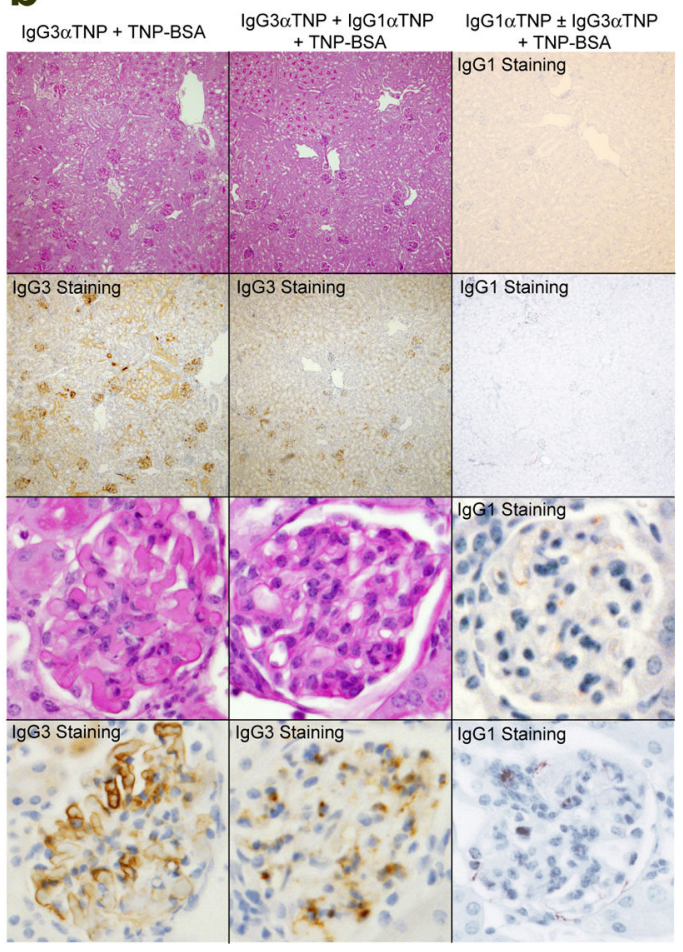

Extended Data Figure 10. Antigen-specific IgG1 can prevent IgG3 immune complex glomerular deposition

BALB/c WT mice were injected i.v.with mouse IgG1 and/or IgG3 anti-TNP mAb with or without s.c.injection of TNP-BSA on days 0 and 1. a. Kidneys were stained with PAS on 
day 2. Representative micrographs from 3 mice/group are shown. b. Kidney serial sections were stained with PAS or for IgG3 or IgG1 (brown pigment). Representative micrographs from 4 mice/group are shown.

\section{Acknowledgments}

We thank Marsha Wills-Karp for C3-deficient mice, Dennis Metzger for J chain-deficient mice, M. Muramatsu for AID-deficient mice, Shozo Izui for a hybridoma that secretes mouse IgG1 anti-TNP mAb, Mike Robson and Lucien Aarden for switch variant hybridomas that secrete mouse IgG1, IgG2a and IgG2b anti-TNP mAbs, Betsy DiPasquale for histological staining, and John Lambris for C5aR antagonist. Research was supported by a U.S Department of Veterans Affairs Merit Award, NIH R01 AI072040, and the University of Cincinnati and Cincinnati Children's Hospital CCTST, all to F.D.F.

\section{References}

1. Nimmerjahn F, Ravetch JV. Fc $\gamma$ receptors as regulators of immune responses. Nat Rev Immunol. 2008; 8:34-47. [PubMed: 18064051]

2. Barrington R, Zhang M, Fischer M, Carroll MC. The role of complement in inflammation and adaptive immunity. Immunol Rev. 2001; 180:5-15. [PubMed: 11414363]

3. Snapper, C.; Finkelman, F. Fundamental Immunology. Paul, WE., editor. Lippincott-Raven; Philadelphia: 1999. p. 837-863.

4. Bruhns $P$, et al. Specificity and affinity of human $\mathrm{Fc} \gamma$ receptors and their polymorphic variants for human IgG subclasses. Blood. 2009; 113:3716-25. [PubMed: 19018092]

5. Jung S, Rajewsky K, Radbruch A. Shutdown of class switch recombination by deletion of a switch region control element. Science. 1993; 259:984-7. [PubMed: 8438159]

6. Roccatello D, et al. Multicenter study on hepatitis C virus-related cryoglobulinemic glomerulonephritis. Am J Kidney Dis. 2007; 49:69-82. [PubMed: 17185147]

7. Nishimura Y, Nakamura H. Human monoclonal cryoimmunoglobulins. I. Molecular properties of IgG3 kappa (Jir protein) and the cryo-coprecipitability of its molecular fragments by papain. $\mathrm{J}$ Biochem. 1984; 95:255-65. [PubMed: 6423624]

8. Abdelmoula M, et al. IgG3 is the major source of cryoglobulins in mice. J Immunol. 1989; 143:52632. [PubMed: 2738401]

9. Finkelman FD, et al. Polyclonal activation of the murine immune system by an antibody to IgD. II. Generation of polyclonal antibody production and cells with surface IgG. J Immunol. 1982; 129:638-46. [PubMed: 6177773]

10. Ravetch JV, Bolland S. IgG Fc receptors. Annu Rev Immunol. 2001; 19:275-90. [PubMed: 11244038]

11. Finkelman FD, Katona IM, Mosmann TR, Coffman RL. IFN- $\gamma$ regulates the isotypes of Ig secreted during in vivo humoral immune responses. J Immunol. 1988; 140:1022-7. [PubMed: 3125247]

12. Erlandsson L, Andersson K, Sigvardsson M, Lycke N, Leanderson T. Mice with an inactivated joining chain locus have perturbed IgM secretion. Eur J Immunol. 1998; 28:2355-65. [PubMed: 9710213]

13. Boot JH, Geerts ME, De Groot ER, Aarden LA. Murine monoclonal isotype switch variants. Detection with rat monoclonal antibodies in ELISA and isolation by sequential sublining. J Immunol Methods. 1988; 106:195-202. [PubMed: 3257512]

14. Dangl JL, et al. Segmental flexibility and complement fixation of genetically engineered chimeric human, rabbit and mouse antibodies. EMBO J. 1988; 7:1989-94. [PubMed: 3138110]

15. Schneider WP, Wensel TG, Stryer L, Oi VT. Genetically engineered immunoglobulins reveal structural features controlling segmental flexibility. Proc Natl Acad Sci U S A. 1988; 85:2509-13. [PubMed: 3128789]

16. Sheerin NS, Springall T, Abe K, Sacks SH. Protection and injury: the differing roles of complement in the development of glomerular injury. Eur J Immunol. 2001; 31:1255-60. [PubMed: 11298352] 
17. van der Neut Kolfschoten M, et al. Anti-inflammatory activity of human IgG4 antibodies by dynamic Fab arm exchange. Science. 2007; 317:1554-7. [PubMed: 17872445]

18. Anthony RM, Kobayashi T, Wermeling F, Ravetch JV. Intravenous gammaglobulin suppresses inflammation through a novel $\mathrm{T}_{\mathrm{H}} 2$ pathway. Nature. 2011; 475:110-3. [PubMed: 21685887]

19. Karsten CM, et al. Anti-inflammatory activity of IgG1 mediated by Fc galactosylation and association of Fc $\gamma$ RIIB and dectin-1. Nat Med. 2012; 18:1401-6. [PubMed: 22922409]

20. Chu SY, et al. Reduction of total IgE by targeted coengagement of IgE B-cell receptor and Fc $\gamma$ RIIb with Fc-engineered antibody. J Allergy Clin Immunol. 2012; 129:1102-15. [PubMed: 22257644]

21. Muramatsu M, et al. Class switch recombination and hypermutation require activation-induced cytidine deaminase (AID), a potential RNA editing enzyme. Cell. 2000; 102:553-63. [PubMed: 11007474]

22. Fulpius T, et al. Glomerulopathy induced by IgG3 anti-trinitrophenyl monoclonal cryfloglobulins derived from non-autoimmune mice. Kidney Int. 1994; 45:962-71. [PubMed: 8007599]

23. Giorgini A, et al. Fc gamma RIII and Fc gamma RIV are indispensable for acute glomerular inflammation induced by switch variant monoclonal antibodies. J Immunol. 2008; 181:8745-52. [PubMed: 19050295]

24. Finkelman FD, Katona IM, Mosmann TR, Coffman RL. IFN-gamma regulates the isotypes of Ig secreted during in vivo humoral immune responses. J Immunol. 1988; 140:1022-7. [PubMed: 3125247]

25. Finkelman FD, et al. Polyclonal activation of the murine immune system by an antibody to IgD. II. Generation of polyclonal antibody production and cells with surface IgG. J Immunol. 1982; 129:638-46. [PubMed: 6177773]

26. Boor P, et al. Complement C5 mediates experimental tubulointerstitial fibrosis. J Am Soc Nephrol. 2007; 18:1508-15. [PubMed: 17389734]

27. Köhl J, et al. A regulatory role for the C5a anaphylatoxin in type 2 immunity in asthma. J Clin Invest. 2006; 116:783-96. [PubMed: 16511606]

28. Strait RT, Morris SC, Finkelman FD. IgG-blocking antibodies inhibit IgE-mediated anaphylaxis in vivo through both antigen interception and Fc gamma RIIb cross-linking. J Clin Invest. 2006;

116:833-41. [PubMed: 16498503] 

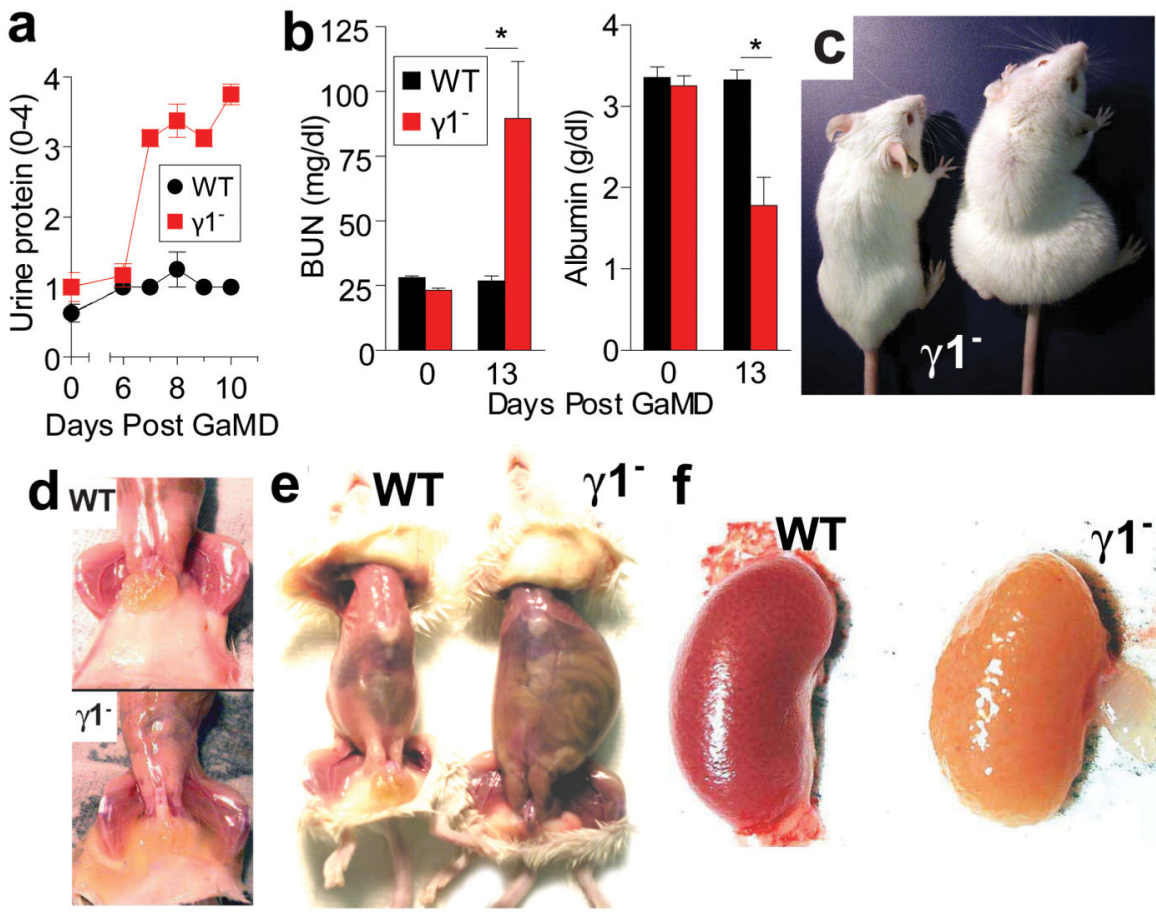

\section{$\gamma 1^{-} \mathbf{f}$}
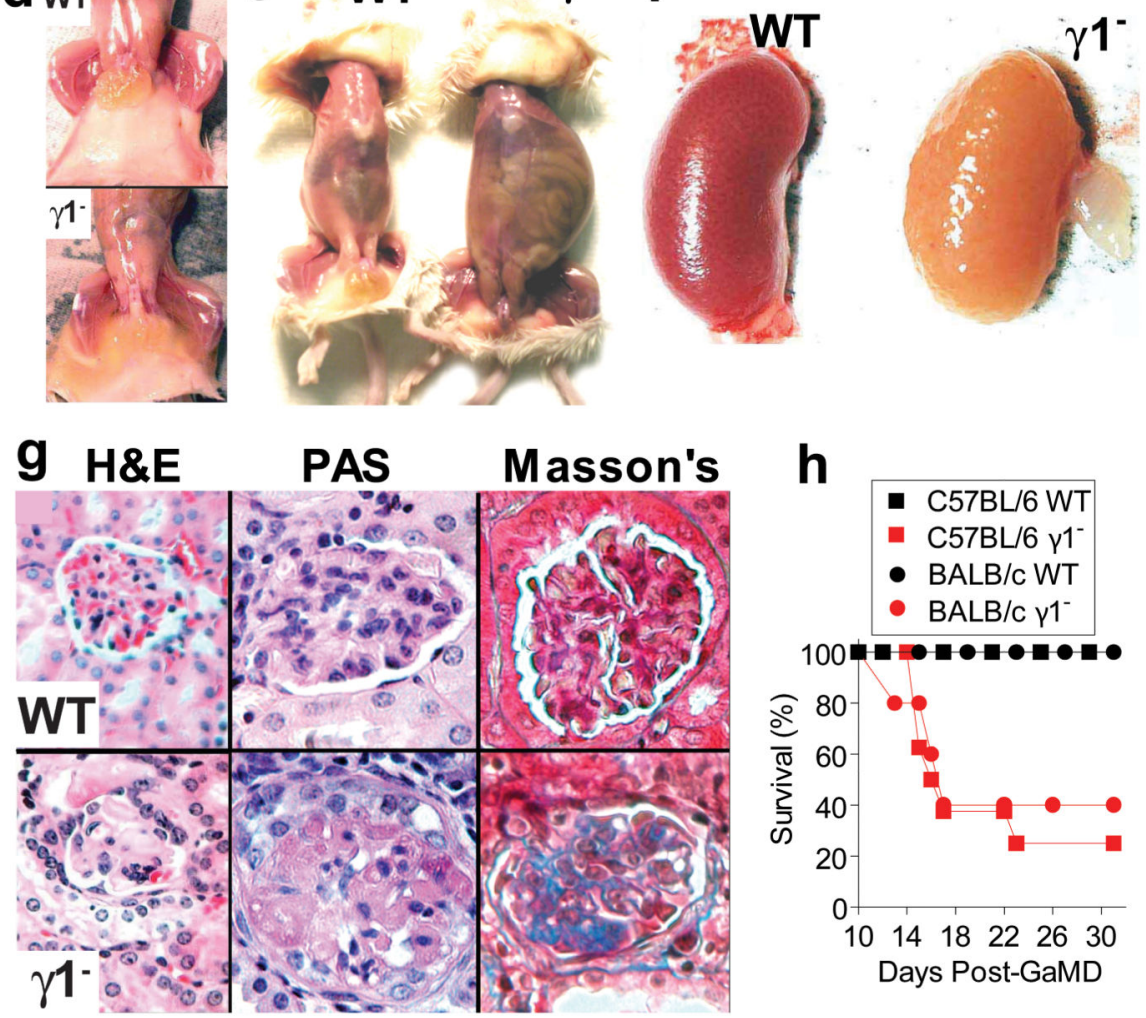

Figure 1. GaMD-immunized $\gamma \mathbf{1}^{-}$mice develop lethal glomerulopathy

WT and $\gamma 1^{-}$mice (4/gp, a-g: 8 or 10/gp, h) were immunized with GaMD. a, Urine protein. b, Serum BUN and albumin. c-g, Representative photographs of mice $13 \mathrm{~d}$ after GaMD immunization demonstrate anasarca (c and d), ascites (e), kidney hypoperfusion (f) and glomerulopathy (g) with $\mathrm{PAS}^{+}$deposits and fibrosis (blue color on Masson's stain) only in $\gamma 1^{-}$mice. $\mathbf{h}$, Survival curves. All figures show means \pm SEMs. Experiments depicted in all figures were repeated with similar results unless otherwise indicated. $* \mathrm{p}<0.05$. $\mathrm{p}$ values were calculated with a non-parametric Mann-Whitney 2-tailed $t$ test for all data shown in all figures. 

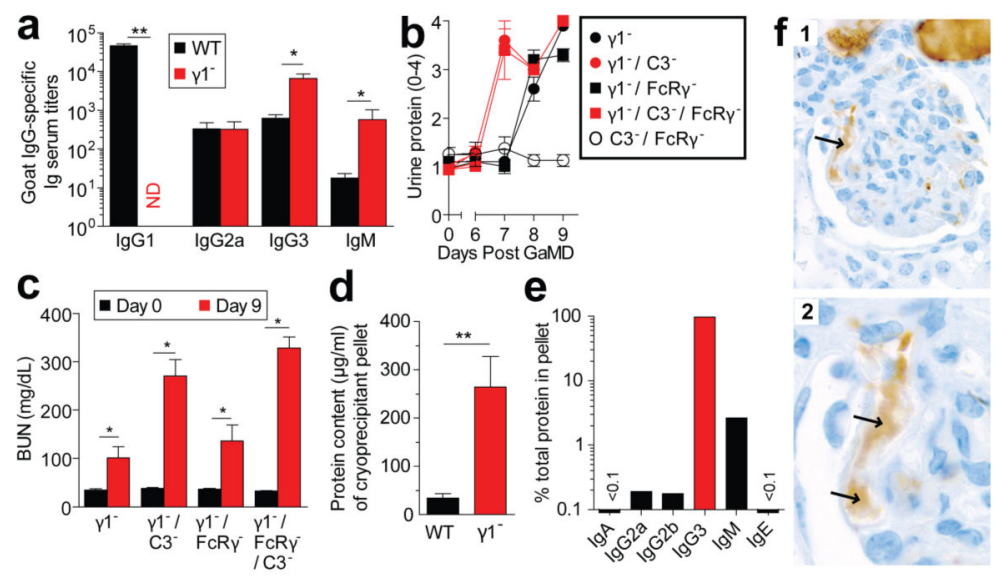

Figure 2. Glomerulopathy in GaMD-immunized $\gamma \mathbf{1}^{-}$mice is complement- and FcR $\gamma$-independent and associated with IgG3 cryoglobulinemia

a. Serum anti-goat IgG titers in WT and $\gamma 1^{-}$mice (4/gp) $8 \mathrm{~d}$ after GaMD immunization. b, c. Urine protein (b) and BUN (c) of GaMD-immunized $\gamma 1^{-}, \gamma 1^{-} / \mathrm{FcR} \gamma^{-}, \gamma 1^{-} / \mathrm{C}^{-}, \mathrm{C}^{-} / \mathrm{FcR} \gamma^{-}$and $\gamma 1^{-} / \mathrm{C} 3-/ \mathrm{Fc} \gamma \mathrm{R}^{-}$mice (5/gp). d, e. Serum cryoprecipitate protein and Ig isotype concentrations 6-7 d after GaMD immunization of WT and $\gamma 1^{-}$mice (7 or 8/gp). Only cryoprecipitates from $\gamma 1^{\text {- }}$ mice contained detectable Ig. f. IgG3 (brown color) in glomerular capillaries (arrows) of $\gamma 1^{-}$mice $8 \mathrm{~d}$ after GaMD (panels 1, low magnification; panel 2, high magnification). * $\mathrm{p}<0.05, * * \mathrm{p}<0.005 . \mathrm{ND}=$ none detected. 

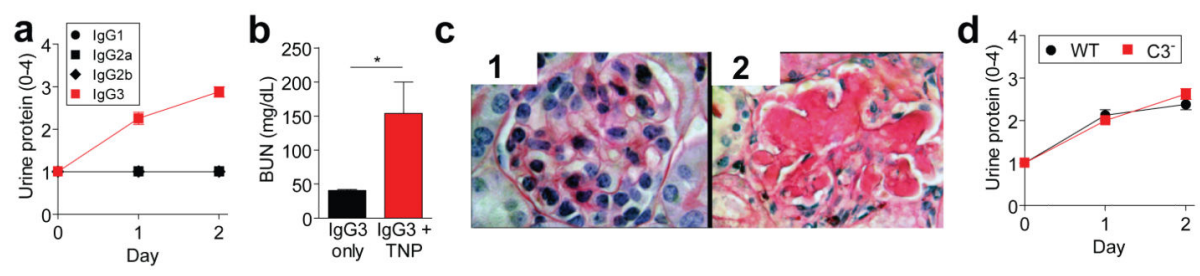

Figure 3. Concurrent injection of WT mice with IgG3 anti-TNP mAb and TNP-goat serum induces glomerulopathy

a, WT mice (4/gp) were injected i.v.with $4 \mathrm{mg}$ of mouse IgG1, IgG2a, IgG2b, or IgG3 antiTNP mAb and s.c. with $100 \mu \mathrm{l}$ of TNP-goat serum on days 0 and 1 . Urine protein measured prior to injections and on $\mathrm{d} 1$ and $\mathrm{d} 2$. b, c, WT mice (4/gp) were injected with mouse IgG3 anti-TNP mAb +/- TNP-goat serum as in "a." Day 2 mouse sera were analyzed for BUN (b). Day 2 kidneys were stained with PAS (c, panel 1: glomerulus from mouse that received only IgG3; panels 2: glomerulus from mouse that received IgG3 + TNP-goat serum).

Representative of 3 mice/group. d, Urine protein for BALB/c WT and C3- mice (4/gp) injected i.v. with $4 \mathrm{mg}$ of IgG3 anti-TNP mAb and s.c. with $400 \mu \mathrm{l}$ of TNP-goat serum on d0 and $1 . * \mathrm{p}<0.05$. 

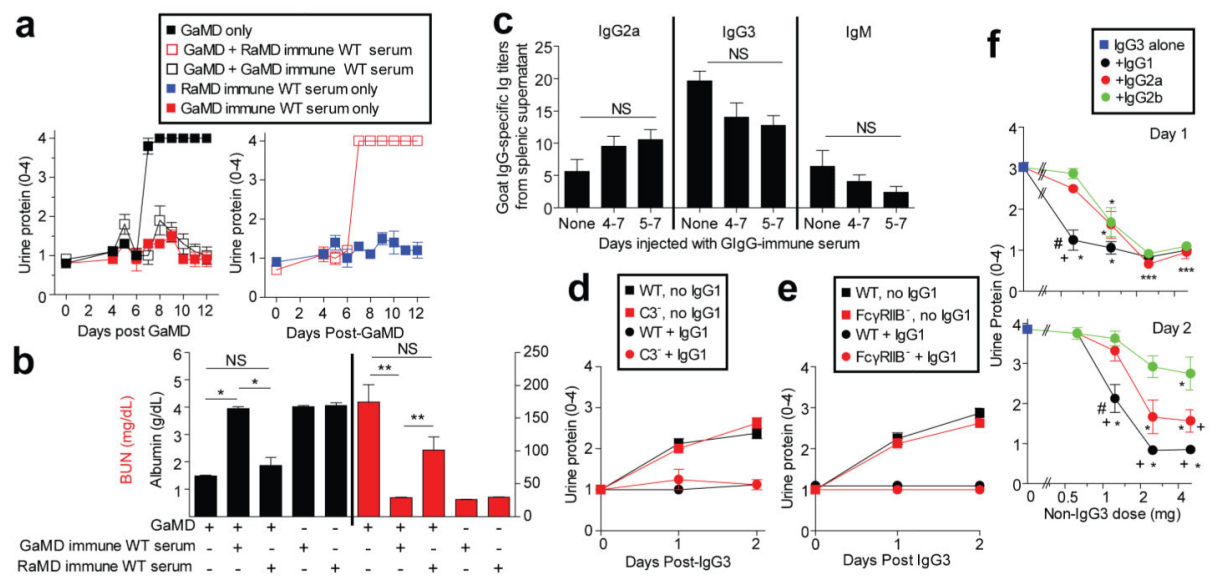

Figure 4. Ag-specific IgG1 prevents IgG3-mediated glomerulopathy BALB/c $\gamma 1^{-}$mice (5/gp) were injected with GaMD on day 0 and/or GaMD-immune or rabbit anti-mouse IgD (RaMD) immune WT serum daily on $\mathrm{d} 4-7$. a,b, Urine protein (a) and $\mathrm{d} 12$ serum albumin and BUN levels $(\mathbf{b}) . * \mathrm{p}<0.05, * * \mathrm{p}<0.005, \mathrm{NS}=$ not significant. c, BALB/c $\gamma 1^{-}$mice (5/gp) were injected with GaMD on $\mathrm{d} 0 \pm$ GaMD immune WT serum daily on $\mathrm{d} 4-7$ or 5-7. Spleens were harvested and cultured on d8; $24 \mathrm{hr}$ culture supernatant IgG2a, $\mathrm{IgG} 3$, and $\operatorname{IgM}$ anti-goat IgG titers were determined. No anti-goat IgG Ab was detected in culture supernatants from non-immune spleen cells. $\mathbf{d}$, WT and C3-deficient (C3-) mice (4/gp) were injected s.c. with $100 \mu \mathrm{l}$ of TNP-goat serum and i.v. with $4 \mathrm{mg}$ of mouse IgG3 anti-TNP $\pm 5 \mathrm{mg}$ of IgG1 anti-TNP mAbs on d0 and 1. Urine was analyzed on d0, 1 and 2. e, WT and Fc $\gamma$ RIIB-deficient (Fc $\gamma$ RIIB $^{-}$) mice (4/gp) were injected s.c. with $100 \mu$ of TNPgoat serum and i.v. with $4 \mathrm{mg}$ of IgG3 anti-TNP $\pm 5 \mathrm{mg}$ of IgG1 anti-TNP on d0 and 1. Urinalysis on $\mathrm{d} 0,1$ and 2. f, BALB/c mice were injected i.v.with $4 \mathrm{mg}$ IgG3 anti-TNP and s.c. with $1.4 \mathrm{mg}$ of TNP-BSA on days 0 and 1 . Some mice were also injected with 0.625 , $1.25,2.5$, or $5 \mathrm{mg}$ of switch variant IgG1, IgG2a or IgG2b anti-TNP mAbs on d0 and 1. Urine protein was determined on d0 (not shown), d1 (upper panel) and d2 (lower panel). Results are pooled from a total of 7 experiments. Group size: IgG3 alone: 19 mice; $0.625 \mathrm{mg}$ of IgG1, IgG2a, or IgG2b: 4 mice; $1.25 \mathrm{mg}$ of IgG1, IgG2a or IgG2b: 8 mice; $2.5 \mathrm{mg}$ of IgG1, IgG2a or IgG2b: 6 mice; $5 \mathrm{mg}$ of IgG1, IgG2a or IgG2b: 8 or 9 mice. The significance of differences between treatment groups was determined with a normal regression model with the covariates: group, dose and group-dose interaction; a t-test was used to evaluate the significance of the difference in least square means for each of these effects. This procedure was used to evaluate urine protein, measured at day 1 and day 2. A p-value less than or equal to 0.05 after applying the Tukey adjustment for multiple comparisons was judged to be significant. \# p $<0.05$ as compared to IgG2a plus IgG3. + p $<0.05$ as compared to IgG2b plus IgG3. *p<0.05 as compared to IgG3 alone. 